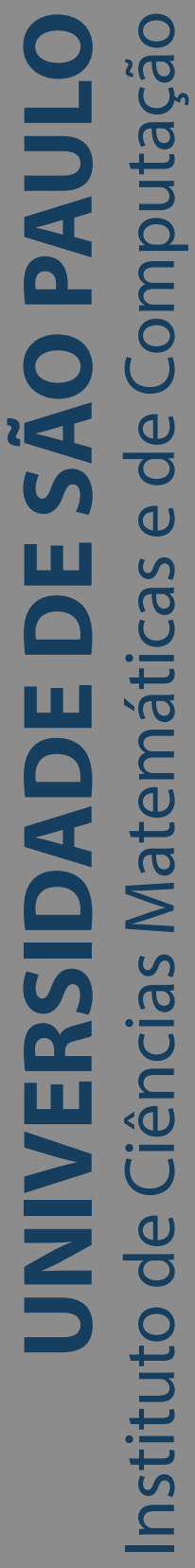

\title{
Aprendizado de Máquina Aplicado no Atendimento de Reclamações de Clientes
}

\section{Luiz Henrique Rowan Peixoto}

Dissertação de Mestrado do Programa de Mestrado Profissional em Matemática, Estatística e Computação Aplicadas à Indústria (MECAI) 

Assinatura:

\title{
Luiz Henrique Rowan Peixoto
}

\section{Aprendizado de Máquina Aplicado no Atendimento de Reclamações de Clientes}

\author{
Dissertação apresentada ao Instituto de Ciências \\ Matemáticas e de Computação - ICMC-USP, \\ como parte dos requisitos para obtenção do título \\ de Mestre - Mestrado Profissional em Matemática, \\ Estatística e Computação Aplicadas à Indústria. \\ VERSÃO REVISADA \\ Área de Concentração: Matemática, Estatística e \\ Computação \\ Orientadora: Profa. Dra. Solange Oliveira Rezende
}


Ficha catalográfica elaborada pela Biblioteca Prof. Achille Bassi e Seção Técnica de Informática, ICMC/USP, com os dados inseridos pelo(a) autor(a)

Peixoto, Luiz Henrique Rowan

Aprendizado de Máquina Aplicado no Atendimento de Reclamações de Clientes / Luiz Henrique Rowan Peixoto; orientadora Solange Oliveira Rezende. -São Carlos, 2021.

$72 \mathrm{p}$.

Dissertação (Mestrado - Programa de Pós-Graduação em Mestrado Profissional em Matemática, Estatística e Computação Aplicadas à Indústria) -- Instituto de Ciências Matemáticas e de Computação, Universidade de São Paulo, 2021.

1. Aprendizado de Máquina. 2. Mineração de Textos. 3. Atendimento de Clientes. 4. Classificação de Textos. I. Rezende, Solange Oliveira, orient. II. Título. 


\title{
Luiz Henrique Rowan Peixoto
}

\section{Machine Learning Applied in Customer Complaint Service}

\begin{abstract}
Master dissertation submitted to the Instituto de Ciências Matemáticas e de Computação - ICMCUSP, in partial fulfillment of the requirements for the degree of the Master - Professional Masters in Mathematics, Statistics and Computing Applied to Industry. FINAL VERSION
\end{abstract}

Concentration Area: Mathematics, Statistics and Computing

Advisor: Profa. Dra. Solange Oliveira Rezende

\section{USP - São Carlos}

February 2022 

Este trabalho é dedicado a todos que buscam de forma incansável aplicar ciência e tecnologia na construção de um mundo melhor. 

À professora Dra Solange Oliveira Rezende pela sabedoria, confiança, motivação e amizade durante toda a orientação do mestrado.

Aos professores do ICMC com os quais tive o prazer de conviver e evoluir durante esta jornada.

À todos os meus queridos familiares por todo o apoio e amor em todos os momentos desta conquista.

À Lucilia pelo amor, companheirismo e incentivos.

Enfim, agradeço a todos que participaram de alguma forma desta conquista. 

"A mente que se abre a uma nova ideia jamais voltará ao seu tamanho original." (Albert Einstein) 



\section{RESUMO}

PEIXOTO, L. H. R. Aprendizado de Máquina Aplicado no Atendimento de Reclamações de Clientes. 2022. 74 p. Dissertação (Mestrado - Mestrado Profissional em Matemática, Estatística e Computação Aplicadas à Indústria) - Instituto de Ciências Matemáticas e de Computação, Universidade de São Paulo, São Carlos - SP, 2022.

A reclamação é uma ação garantida por entidades de proteção ao consumidor, e com a digitalização crescente da sociedade e a popularização das plataformas digitais de reclamações, têm-se um aumento crescente das reclamações de clientes nestas plataformas. A escalada das reclamações em ambientes digitais tratadas incorretamente impactam a imagem das empresas e geram uma necessidade cada vez mais latente de capturar, processar, analisar e gerar conhecimento usando automatizações. Com este cenário, este trabalho propõe a utilização de técnicas de Mineração de Textos e Aprendizado de Máquina em um fluxo de triagem de reclamações com objetivo de minimizar a probabilidade de não-resolução das reclamações de clientes de serviços financeiros. A abordagem proposta é avaliada por meio de 3 arquiteturas distintas de complexidade, sendo que para modelo base utilizou-se o Naive-Bayes SVM, para o intermediário foi utilizado as embeddings FastText com classificador Multi-layer Perceptron e como técnica desafiante foi utilizado o modelo de linguagem DistilBERT. A utilização apenas da narrativa da reclamação do consumidor apresentou resultado pouco relevante na discriminação da resolutividade, porém quando agregado a narrativa de atendimento da empresa os modelos performaram consideravelmente bem e podem ser aplicados em uma estratégia de atendimento. Os resultados mostraram que os métodos podem gerar valor em sistemas de apoio à tomada de decisão na área operacional das empresas e podem auxiliar as mesmas no atendimento de seus clientes, elevando o nível de satisfação dos consumidores e reduzindo o risco de imagem da empresa. A escolha de um bom modelo de predição depende da estratégia de atuação da operação de atendimento, sendo que a capacidade de ordenação do risco torna-se preponderante nessa escolha.

Palavras-chave: Mineração de Textos; Aprendizado de Máquina; Atendimento de Clientes. 



\section{ABSTRACT}

PEIXOTO, L. H. R. Machine Learning Applied in Customer Complaint Service. 2022. 74 p. Dissertação (Mestrado - Mestrado Profissional em Matemática, Estatística e Computação Aplicadas à Indústria) - Instituto de Ciências Matemáticas e de Computação, Universidade de São Paulo, São Carlos - SP, 2022.

The complaint is an action guaranteed by consumer protection entities, and with the increasing digitization of society and the popularization of digital complaint platforms, there is a growing increase in customer complaints in these platforms. The escalation and the incorrectly handled complaints in the digital platforms impact the image of companies and generate an increasingly latent need to capture, process, analyze and generate knowledge using automations. With this scenario, this dissertation proposes the use of Text Mining and Machine Learning techniques in a complaints triage flow in order to minimize the probability of non-resolution of complaints from financial services customers. The proposed approach is evaluated through 3 different architectures of complexity, with the Naive-Bayes SVM that was used as a baseline model, the FastText that was used as the intermediate model and the DistilBERT that was used as a challenging technique. The use of only the narratives of the consumer's complaints presented little relevant result in the discrimination of the resoluteness, however when added to the narrative of the company's service, the models performed considerably well and can be applied in a service strategy. The results showed that the methods can generate value in decision-making support systems in the operational area of companies and can help them in serving their customers, raising the level of consumer satisfaction and reducing the risk of the company's image. The choice of a good prediction model depends on the performance strategy of the customer service, and the ability to sort the risk becomes preponderant in this choice.

Keywords: Text Mining; Machine Learning; Customer Service. 



\section{LISTA DE ILUSTRAÇÕES}

Figura 1 - Reclamações por segmento. Fonte: Senacon (2020) . . . . . . . . . . . . . 29

Figura 2 - Índice de resolutividade por segmento. Fonte: Senacon (2020) . . . . . . . 29

Figura 3 - Processo de Mineração de Textos. Fonte: Rezende (2003) . . . . . . . . . . 32

Figura 4 - Autoencoder. Gerado pelo autor. . . . . . . . . . . . . . 36

Figura 5 - Representação de entrada do BERT. Fonte: Devlin et al. (2018) . . . . . . . 38

Figura 6 - Etapas de treinamento do BERT. Fonte: Devlin et al. (2018) . . . . . . . . . 39

Figura 7 - Processo de MT instanciado. Gerado pelo autor. . . . . . . . . . . . . 46

Figura 8 - Dados coletados no ReclameAQUI. Fonte: ReclameAQUI (2021) . . . . . . 47

Figura 9 - Exemplos de atendimento por resposta padronizada. Gerado pelo autor. . . . 48

Figura 10 - Distribuição das respostas em relação ao centroide. Gerado pelo autor. . . . 48

Figura 11 - Exemplos de limpeza dos dados. Gerado pelo autor. . . . . . . . . . . . . 49

Figura 12 - Evolução da taxa de aprendizagem para os modelos 1, 2 e 3. Gerado pelo autor. 51

Figura 13 - Processo de atendimento proposto. Gerado pelo autor. . . . . . . . . . . . 54

Figura 14 - Fluxo das reclamações e avaliação dos classificadores. Gerado pelo autor. 57

Figura 15 - Distribuição da variável de resolutividade. Gerado pelo autor. . . . . . . . . 58

Figura 16 - Histograma de quantidade de palavras nas reclamações e respostas. Gerado pelo autor. . . . . . . . . . . . . . . . 5 58

Figura 17 - Frequência das 50 palavras mais comuns nas reclamações e respostas. Gerado pelo autor. . . . . . . . . . . . . . . . . . 59

Figura 18 - Nuvem de palavras das reclamações e das respostas respectivamente. Gerado pelo autor. . . . . . . . . . . . . . . . . . 59

Figura 19 - MOD1: Curva ROC e melhor limiar (NBSVM, FastText e DistilBERT). Gerado pelo autor. . . . . . . . . . . . . . . . 6 60

Figura 20 - MOD1: Estatística KS (NBSVM, FastText e DistilBERT). Gerado pelo autor. 61

Figura 21 - MOD1: Acurácia por decil de score (NBSVM, FastText e DistilBERT).

Gerado pelo autor. . . . . . . . . . . . . . . . . 62

Figura 22 - MOD2: Curva ROC e melhor limiar (NBSVM, FastText e DistilBERT). Gerado pelo autor. . . . . . . . . . . . . . . 63

Figura 23 - MOD2: Estatística KS (NBSVM, FastText e DistilBERT). Gerado pelo autor. 64

Figura 24 - MOD2: Acurácia por decil de score (NBSVM, FastText e DistilBERT).

Gerado pelo autor. . . . . . . . . . . . . . . . . . . . 64

Figura 25 - Dashboard do caso de uso "Voz del cliente". . . . . . . . . . . . . . . . 74 



\section{LISTA DE TABELAS}

Tabela 1 - Comparativo entre trabalhos relacionados . . . . . . . . . . . 43

Tabela 2 - Matriz de confusão . . . . . . . . . . . . . . . 52

Tabela 3 - Métricas de treino e teste para MOD1 e MOD2 . . . . . . . . . . . 60

Tabela 4 - Resultados dos modelos em MOD1 . . . . . . . . . . . . . . 61

Tabela 5 - Resultados dos modelos em MOD2 . . . . . . . . . . . . . . . 63 

ADR Alternative Dispute Resolution

AED Análise Exploratória de Dados

AM Aprendizado de Máquina

BACEN Banco Central

BERT Bidirectional Encoder Representations from Transformers

BoW Bag-of-Words

CDC Código de Defesa do Consumidor

CNPC Conselho Nacional de Previdência Complementar

CNSP Conselho Nacional dos Seguros Privados

CVM Comissão de Valores Mobiliários

DistilBERT Distilled version of BERT

DTM document-term matrix

eWOM electronic word-of-mouth

KNN K-Nearest Neighbor

LIWC Linguistic Inquiry and Word Count

LSA Latent Semantic Analysis

MLM Masked Language Model

MLP Multilayer Perceptron

MOD1 Modelagem com Dados Textuais de Reclamações

MOD2 Modelagem com Dados Textuais de Reclamações e Respostas

MT Mineração de Textos

NB Naive Bayes

NBSVM Naive Bayes SVM

NPS Net Promoter Score

NSP Next Sentence Prediction

ODI Outcome-Driven Innovation

ODR Online Dispute Resolution

PREVIC Superintendência Nacional de Previdência Complementar

PROCON Programa de Proteção e Defesa do Consumidor

RNA Redes Neurais Artificiais

SAC Serviço de Atendimento ao Consumidor 
Senacon Secretaria Nacional do Consumidor

SFN Sistema Financeiro Nacional

SMO Sequential minimal optimization

SUSEP Superintendência de Seguros Privados

SVM Support Vector Machine

TF-IDF Term Frequency-inverse Document Frequency 
INTRODUÇÃO $\ldots \ldots \ldots \ldots \ldots \ldots \ldots \ldots$

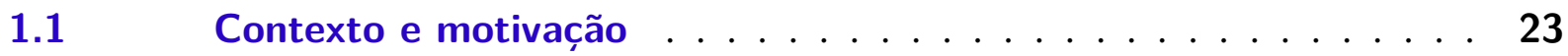

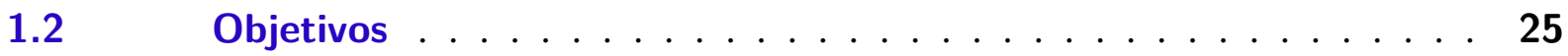

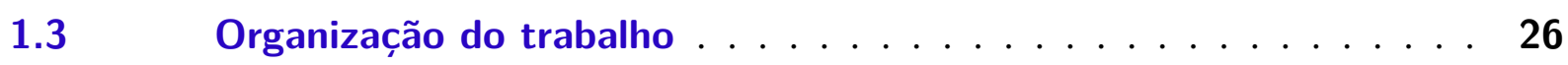

2 FUNDAMENTOS E TRABALHOS RELACIONADOS . . . . . . . 27

2.1 Reclamações e satisfação do cliente . . . . . . . . . . . . 27

2.1.1 Canais de atendimento para reclamações . . . . . . . . . . . 27

2.1.2 Satisfação do cliente . . . . . . . . . . . . . . . . 30

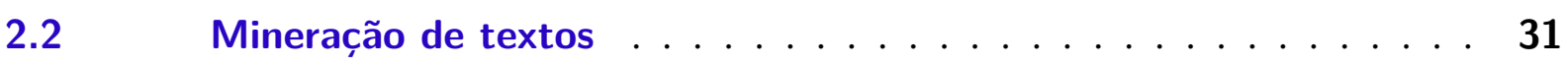

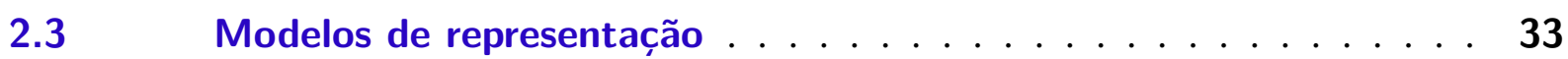

2.3.1 Modelo Bag-of-Words . . . . . . . . . . . . . . . . 33

2.3.2 Modelos de linguagem . . . . . . . . . . . . . . . . . . . 34

2.3.2.1 Modelos de word embeddings . . . . . . . . . . . . . . . . . 35

2.3.2.2 Modelos de Transformers . . . . . . . . . . . . . . . . . . . 37

2.3.2.3 Bidirectional Encoder Representations from Transformers (BERT) . . . . 37

$2.4 \quad$ Aprendizado de máquina para mineração de textos . . . . . . . . 39

2.4.1 Naive Bayes SVM . . . . . . . . . . . . . . . . . . . 39

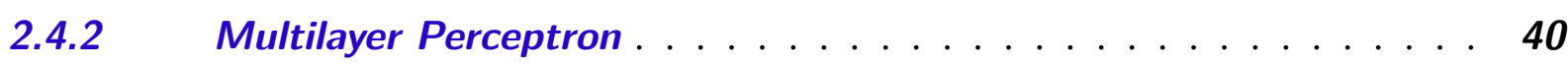

2.5 Trabalhos relacionados $\ldots \ldots \ldots \ldots \ldots \ldots \ldots$

3 ATENDIMENTO DE RECLAMAÇÕES DE CLIENTES USANDO MINERAÇÃO DE TEXTOS . . . . . . . . . . . . . 45

$3.1 \quad$ Mineração de textos em reclamações de clientes . . . . . . . . 45

3.1.1 Problema de reclamações de clientes . . . . . . . . . . . . . 46

3.1.1.1 Coleta de dados de reclamações . . . . . . . . . . . . . . . . 47

3.1.1.2 Análise de similaridade das respostas . . . . . . . . . . . . . . 47

3.1.2 Pré-processamento de reclamações . . . . . . . . . . 49

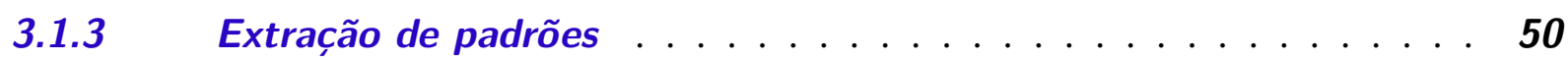

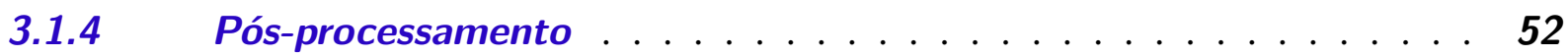

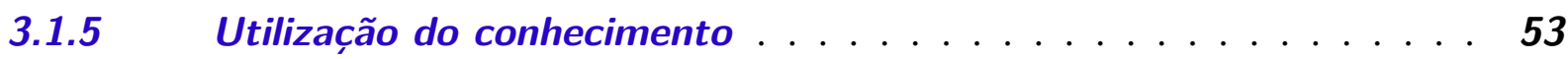

3.2 Proposta de atendimento com triagem de reclamações . . . . . 53

$3.3 \quad$ Considerações finais . . . . . . . . . . . . . . . 55 


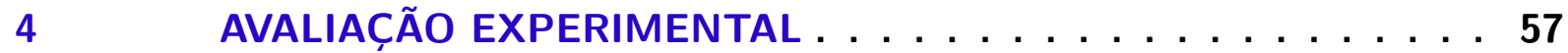

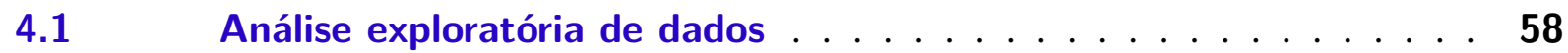

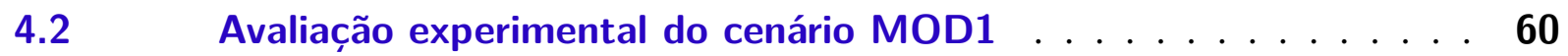

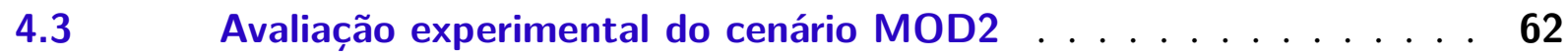

$4.4 \quad$ Considerações finais . . . . . . . . . . . . . . . . . . . 64

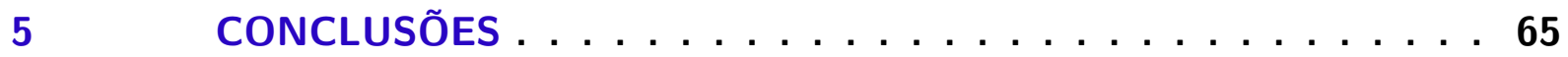

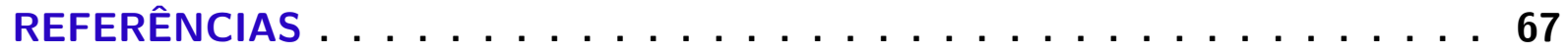

APÊNDICE A CASO DE USO APLICADO NA INDÚSTRIA . . . . 73 


\section{1}

\section{INTRODUÇÃO}

\subsection{Contexto e motivação}

O advento da internet, a proliferação da digitalização, das mídias sociais e dos dispositivos móveis na sociedade alavancaram nos últimos anos a amplitude e o impacto da expressão de opinião individual. As opiniões caracterizam-se por ser uma manifestação de uma visualização pessoal, representando o estado de espírito e a atitude de um indivíduo ou de um grupo em relação a uma determinada realidade (SEZGEN; MASON; MAYER, 2019; EKINCI; CALDERON; SIALA, 2016; YANG et al., 2019). Por meio da internet, as opiniões de outros consumidores oferecem a possibilidade de avaliação de um produto ou serviço baseado nas experiências da própria comunidade de consumidores, o que é conceituado como electronic word-of-mouth (eWOM) (HENNIG-THURAU et al., 2004; SOUSA et al., 2020) ou no popular "boca-a-boca eletrônico".

Entre as opiniões manifestadas na internet para fins de consumo, destacam-se negativamente para as empresas as reclamações de consumidores, que são resultados de sentimentos de insatisfação em relação a produtos e serviços contratados (EKINCI; CALDERON; SIALA, 2016). A insatisfação é decorrente de uma expectativa não atendida em uma relação de consumo que pode ser gerada pela ausência de qualidade do produto, por uma cobrança indevida, falhas na entrega ou habilitação do serviço, falta de entendimento dos termos contratuais, suporte inadequado, entre outras.

Considerando a insatisfação do consumidor, a reclamação é uma ação garantida pelo Código de Defesa do Consumidor (CDC) por meio de um canal de atendimento (BRASIL, 2008). Os canais de atendimento para reclamações de consumo podem ser agrupadas em algumas categorias. O Serviço de Atendimento ao Consumidor (SAC) é um canal de atendimento obrigatório por lei, sendo este disponibilizado pelo prestador do serviço. Geralmente é exigido que o cliente apresente sua reclamação no SAC antes de qualquer outro canal atendimento. As 
agencias reguladoras são entidades da administração pública responsáveis pela regulação de setores específicos. Estas disponibilizam canais de atendimento ao consumidor para setores como transportes terrestre, aquaviário e aéreo, gestão de recursos naturais, produção audiovisual, planos de saúde e vigilância sanitária (GUERRA; SALINAS, 2020). O Programa de Proteção e Defesa do Consumidor (PROCON) é um órgão administrativo extrajudicial do Poder Executivo, que tem como funções o acompanhamento e fiscalização das relações ocorridas entre fornecedores e consumidores garantindo a correta execução do CDC, evitando assim a atuação do Poder Judiciário (OLIVEIRA et al., 2016). As Online Dispute Resolution (ODR) são meios eletrônicos de resolução de conflitos que podem ter funções jurisdicionais e extrajurisdicionais (GUERRA; SALINAS, 2020), e estes podem ser geridos por agencias reguladoras, PROCON, ou por empresas do setor privado.

De acordo com Schmidt-Kessen, Nogueira e Gamito (2020), as plataformas de ODR são mais conhecidas e mais importantes no Brasil do que nos países da União Européia. Elas permitem a interlocução direta entre consumidores e empresas para solução de conflitos de consumo pela internet. As funções das ODR não são apenas extrajudiciais, mas também extrajurisdicionais, já que visam subsidiar iniciativas regulatórias das agências que extrapolam a atividade de resolução de conflitos (GUERRA; SALINAS, 2020).

As ODRs têm como finalidade disponibilizar de forma acessível aos consumidores uma ferramenta automatizada de gestão de reclamações e reputação das empresas. De acordo com Marques (2019), o acesso as ODRs é um passo fundamental para cada vez mais se afastar o Brasil da "cultura da sentença" e aproximá-lo da tão desejada "cultura da pacificação". Essas plataformas garantem que a reclamação gerada pelo reclamante chegue até o reclamado, além de acompanhar o andamento e gerar indicadores. É considerado uma visão moderna em relação ao acesso à justiça, principalmente quando uma intervenção judicial não pode ser considerada sequer necessária ou útil.

No Brasil, as plataformas de ODR têm ganhado relevância e influência (SOUSA et al., 2020), e entre as plataformas com maior popularidade destaca-se o ReclameAQUI (2021) que entre 30/04/2021 e 30/07/2021 foi o $11^{\circ}$ site brasileiro mais acessado, sendo que os usuários fizeram em média 2,3 visitas em páginas distintas com um tempo médio de 2 minutos e 57 segundos nas interações (ALEXA, 2021). O ReclameAqui possui uma base de 15 milhões de consumidores e 120 mil empresas cadastradas, com uma média de 42 milhões de visualizações mensais. A plataforma do ReclameAQUI não divulga a quantidade de reclamações que o seu serviço recebe ao todo, porém divulga por empresa, e levantando a quantidade de reclamações dos 4 principais bancos brasileiros nos últimos 12 meses, têm-se em aproximadamente 237 mil reclamações recebidas.

Dado que a reclamação é uma ação garantida por entidades de proteção ao consumidor, a digitalização constante da sociedade e a popularização das plataformas de ODR resultam em aumento constante das reclamações de clientes em ambientes digitais. Para as empresas, 
o aumento constante de reclamações torna o processo de analisar, direcionar e tratar essas reclamações manualmente insustentável (GALITSKY; GONZÁLEZ; CHESÑEVAR, 2009). A escalada das reclamações em ambientes digitais tratadas incorretamente impactam a imagem das empresas e gera uma necessidade cada vez mais latente de capturar, processar, analisar e gerar conhecimento usando técnicas de Mineração de Textos (MT) e Aprendizado de Máquina (AM) (JOUNG et al., 2019; SOUSA et al., 2020). Tratar as reclamações no tempo certo e na forma correta pode gerar satisfação, e de acordo com Reichheld (2003), há uma forte correlação entre a taxa de crescimento de uma empresa e a porcentagem de seus clientes que são "promotores", ou seja, clientes satisfeitos propensos a recomendar a empresa a um amigo ou colega.

O uso de técnicas de MT para extração e representação textual em conjunto com algoritmos de AM para extração de padrões em textos tem-se mostrado uma abordagem bastante utilizada para resolução de problemas dos consumidores e de conflitos entre consumidores e empresas. Essas técnicas tem sido empregadas para análise de sentimentos, sumarização de reclamações, tratamento especial para problemas complexos, identificação de problemas generalizados, desenvolvimento de novos produtos, entre outros (KRISHNA et al., 2019; GONÇALVES, 2016; CAROSIA; COELHO; SILVA, 2020; JOUNG et al., 2019; SOUSA et al., 2020; HU; LIU, 2004a; HU; LIU, 2004b; YANG et al., 2019). Estes e outros trabalhos serão detalhados no Capítulo 2.

\subsection{Objetivos}

Diante das dificuldades de operacionalização em escala, dos custos associados e da eficácia das empresas em gerar satisfação no atendimento das reclamação dos clientes, este trabalho tem como objetivo geral avaliar o uso de técnicas de MT e AM no processo de atendimento de reclamações de clientes insatisfeitos com produtos e serviços.

Os dados utilizados neste trabalho contemplam reclamações finalizadas de consumidores de serviços financeiros na plataforma ReclameAQUI. Combinando os dados e a metodologia proposta, este trabalho visa responder as seguintes questões de pesquisa específicas:

1. É possível indicar a baixa probabilidade de resolução de uma reclamação no momento em que ela foi gerada?

2. É possível indicar a baixa probabilidade de resolução de uma reclamação combinando a narrativa da reclamação e a narrativa da resposta da empresa?

3. É possível utilizar dados não-estruturados textuais para direcionar o fluxo de atendimento das reclamações utilizando AM?

4. O emprego de técnicas mais sofisticadas como modelos de linguagem podem agregar mais performance na classificação de resolutividade em relação a técnicas mais simples? 
5. Baseado nas respostas anteriores, as técnicas avaliadas podem auxiliar as empresas no atendimento de seus clientes elevando o nível de satisfação dos consumidores e reduzindo o risco de imagem da empresa?

\subsection{Organização do trabalho}

Esta dissertação está organizada no seguinte formato:

- No Capítulo 1 foram apresentadas a contextualização, a motivação do tema e as perguntas que este trabalho tem como objetivo responder.

- No Capítulo 2 é apresentado um resumo dos fundamentos e dos principais trabalhos relacionados aos temas do presente trabalho.

- No Capítulo 3 é apresentada uma metodologia de aplicação de modelos utilizando técnicas de MT com objetivo de triar reclamações com baixa probabilidade e também um processo de atendimento que utiliza esses modelos.

- No Capítulo 4 são apresentados os resultados da avaliação experimental que embasam as respostas das perguntas que norteiam o trabalho.

- No Capítulo 5 são apresentadas as conclusões da dissertação, discutindo as limitações encontradas e propostas de ideias para trabalhos futuros.

- Finalmente são apresentados a bibliografia e um apêndice que mostra a aplicação prática na indústria de conceitos estudados neste trabalho. 


\section{FUNDAMENTOS E TRABALHOS RELACIONADOS}

Neste capítulo são abordadas as reclamações como um importante instrumento de proteção do consumidor, os métodos para monitoramento de satisfação dos consumidores, o processo de mineração de textos aplicados em problemas de classificação e as técnicas para representação e classificação de textos. Ao final é feito um levantamento de trabalhos com aplicações práticas usando MT, AM e dados de satisfação ou reclamações de consumidores. Estes fundamentos e os trabalhos relacionados têm como objetivo criar a base necessária para entendimento da metodologia, dos resultados e das conclusões deste trabalho que serão apresentados nos próximos capítulos.

\subsection{Reclamações e satisfação do cliente}

Nesta seção são apresentados os canais por onde os clientes podem reclamar e exigir seus direitos, os principais conceitos que embasam a satisfação do cliente, e importância do atendimento e resolutividade nas relações de consumo tanto para as empresas quanto para os consumidores.

\subsubsection{Canais de atendimento para reclamações}

Os canais de atendimento ao consumidor geridos pelas empresas reclamadas são garantidos pela lei 8.078, regulamentada em 30 de julho de 2008 (BRASIL, 2008). A lei fixa normas gerais sobre o SAC, garantindo aos clientes informação adequada e clara sobre os serviços prestados como forma de manter-se protegido contra práticas abusivas ou ilegais impostas no fornecimento desses serviços. O SAC é o canal de comunicação direto com a empresa e geralmente é por onde o cliente começa o processo para obter a resolução de sua reclamação, antes de ir a uma agência reguladora. 
As agências reguladoras são entidades da administração pública Brasileira e ingressaram ao longo dos anos 90 com poderes de regulação, normatização, controle e fiscalização sobre setores variados da economia (GUERRA; SALINAS, 2020). Se enquadram nesta categoria agências como Agência Nacional de Telecomunicações (ANATEL), Agência Nacional de Energia Elétrica (ANEEL), Agência Nacional de Saúde Suplementar (ANS). Um fato importante é que os índices de reclamações feitas por meio dessas agências tem crescido constantemente, enquanto que as taxas de resolutividade permanecem modestas (GUERRA; SALINAS, 2020).

No Sistema Financeiro Nacional (SFN) existem várias agências reguladoras como Banco Central (BACEN), Comissão de Valores Mobiliários (CVM), Superintendência de Seguros Privados (SUSEP), Superintendência Nacional de Previdência Complementar (PREVIC), além dos órgãos normativos como Comissão de Valores Mobiliários (CVM), Conselho Nacional dos Seguros Privados (CNSP) e Conselho Nacional de Previdência Complementar (CNPC) (BCB2021, 2021a). Estas instituições tem como função principal a garantia da segurança do ambiente de negociações interno do país e a estabilidade do mercado nacional, afim de tornar os investimentos no país mais viáveis e atrativos. Dentro desse cenário, essas instituições exercem um papel de moderador das reclamações dos consumidores, com o objetivo de usar esses dados na fiscalização do SFN (BCB2021, 2021b).

A Fundação de Proteção e Defesa do Consumidor (PROCON) é uma fundação presente nos estados e municípios com personalidade jurídica de direito público assegurada pela Constituição Federal de 1988. Sua função é garantir as relações de consumo e a ordem econômica por meio do CDC (Artigo 105 - Lei 8.078/90) (OLIVEIRA et al., 2016). Dentre as principais atividades do PROCON, destacam-se a orientação da população, campanhas informativas sobre direito dos consumidores, registro de reclamações, conciliação entre as partes e fiscalização das relações de consumo. Somente em 2019 os PROCONS realizaram mais de 2,5 milhões de atendimentos, sendo quase 1,9 milhão de reclamações e denuncias (SENACON, 2020).

As ODRs, são plataformas digitais de resolução de conflitos nas relações de consumo. Estas plataformas podem ser geridas pelo poder público ou pela iniciativa privada. Além disso, caracterizam-se por disponibilizar um serviço na internet, pelo acompanhamento das reclamações desde a originação até a conclusão, e por ser uma alternativa de resolução de conflitos fora da regulação estatal, o que é conceituado como Alternative Dispute Resolution (ADR) (KAUFMANN-KOHLER; SCHULTZ, 2004). Essas plataformas fazem gestão de um fluxo sequencial de comunicações entre as partes iniciando pela coleta e organização das informações do conflito, assistindo e mediando a negociação, e arbitrando quando não há resolução entre as partes (ARBIX, 2015). Devido a praticidade, a confidencialidade e a possibilidade de resolução sem intervenção da justiça, as ODRs são ideais para serem usados em setores muito demandados na justiça, como o financeiro, a telefonia e o varejo.

Em 2014 foi lançada pela Secretaria Nacional do Consumidor (Senacon), subordinada ao Ministério da Justiça do Brasil, a plataforma de ODR consumidor.gov.br. Esta plataforma é 
um serviço público e gratuito que permite a comunicação direta entre consumidores e empresas para solução de conflitos de consumo pela internet. Desde o seu início, a plataforma já registrou mais de 2,4 milhões de reclamações, e conta com uma base de 1,8 milhão de usuários cadastrados e mais de 600 empresas credenciadas. Atualmente, $80 \%$ das reclamações registradas no consumidor.gov.br são solucionadas pelas empresas participantes, que respondem às demandas dos consumidores em um prazo médio de 6,5 dias (SENACON, 2020).

Na Figura 1 é possível ver os 5 principais segmentos que geram reclamações no consumidor.gov.br, enquanto que na Figura 2 são mostradas as resolutividades destes segmentos.

Figura 1 - Reclamações por segmento. Fonte: Senacon (2020)

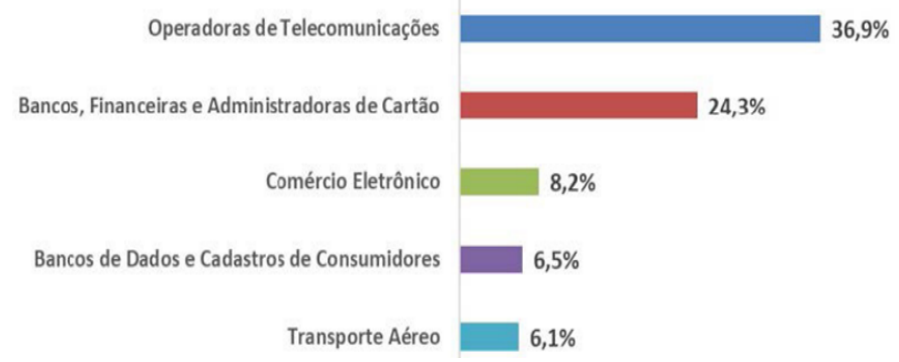

Figura 2 - Índice de resolutividade por segmento. Fonte: Senacon (2020)

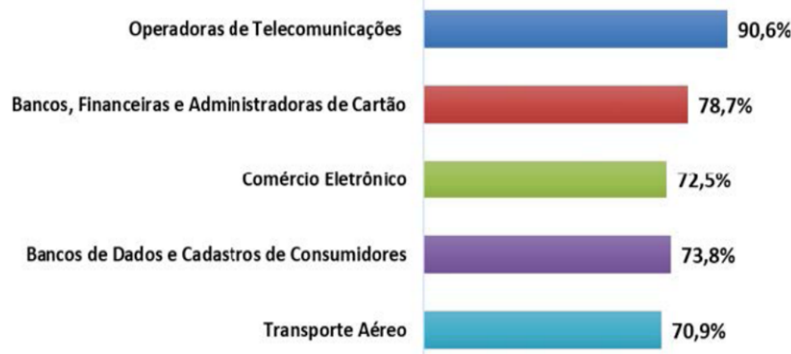

Dentre as plataformas brasileiras de ODR geridas pela iniciativa privada, destaca-se o ReclameAQUI devido a grande quantidade de usuários, empresas cadastradas, visualizações e reclamações mensais. A plataforma foi criada pelo empresário Maurício Vargas que em 2001 teve um problema com uma companhia aérea e perdeu um importante negócio. Ele não encontrou um canal para expor sua insatisfação e alertar outros consumidores, e desta forma teve a ideia de criar o ReclameAQUI (RECLAMEAQUI, 2021). Para gerar engajamento das empresas e dos clientes na plataforma, o ReclameAQUI gera e exibe os indicadores de reputação das empresas. Além disso, a plataforma confere anualmente o prêmio ReclameAQUI, que é dividido por segmento de atuação das empresas e tem como objetivo mostrar quais empresas estão atuantes no atendimento e na resolução de conflitos com seus clientes.

A plataforma tem como função o cadastro e a condução das reclamações efetuadas. Porém, o maior serviço que este tipo de plataforma fornece não é individual e sim coletivo. No ReclameAQUI, mais de 600 mil pessoas pesquisam reputações de empresas antes de realizar 
uma compra ou contratar um serviço (RECLAMEAQUI, 2021). O objetivo é, portanto, persuadir as empresas a corrigir seus erros como forma de melhorar os indicadores que podem levar a deterioração da imagem da mesma perante aos consumidores propensos a consumir seus produtos. Apesar de se auto-declarar como um projeto $100 \%$ gratuito e em benefício ao público, a plataforma comercializa cursos, workshops e ferramentas de gestão de equipes, monitoramento e SAC, sempre relacionados ao atendimento ao consumidor

Para execução deste trabalho, foram utilizadas as reclamações coletadas na plataforma ReclameAQUI, pois a mesma disponibiliza em seu site todo o conteúdo dos textos das reclamações, respostas, réplicas e considerações finais. Fornecem também o status de andamento e quando finalizadas, é possível consultar se a reclamação foi resolvida, se o cliente voltaria a fazer negócio com a empresa e qual o grau de satisfação do cliente quanto ao atendimento.

\subsubsection{Satisfação do cliente}

A satisfação nas relações de consumo é um sentimento de prazer ou de desapontamento percebido pelo consumidor quando ele adquire um produto ou serviço e compara com suas expectativas (SEZGEN; MASON; MAYER, 2019). Nesse sentido, para aumentar a satisfação do cliente, as empresas primeiro precisam reconhecer a conotação dessas expectativas (LIU; WAN; SU, 2019). Também denominada como experiência do cliente, esse sentimento é a percepção definida a partir das crenças do consumidor no que diz respeito ao serviço prestado ou experimentado. Como a satisfação está ligada aos pré-requisitos do consumidor, diferentes grupos de consumidores podem apresentar graus de satisfação distintos para uma mesma experiência. Em Sezgen, Mason e Mayer (2019), os autores sugerem avaliar satisfação de um serviço por segmentos de clientes, como classe social ou origem.

A satisfação dos clientes pode gerar indicadores de grande utilidade para as empresas e ajudar a descobrir se um produto ou serviço está atendendo às expectativas dos mesmos. Nesse cenário um indicador amplamente utilizado para mensurar satisfação de clientes é o Net Promoter Score (NPS) (REICHHELD, 2003). O NPS é utilizado na indústria em virtude da sua simplicidade, confiabilidade e flexibilidade (XAVIER, 2019). Tem como pergunta base: "Qual é a probabilidade de você recomendar a nossa empresa / produto / serviço a um amigo ou colega?". A pontuação para esta resposta é dada por uma escala de 0 a 10, e de acordo com as notas, os consumidores são classificados em 3 grupos: detratores ( 0 a 6$)$, neutros ( 7 a 8 ) e promotores $(9$ e 10) (REICHHELD, 2003).

Com um mercado cada vez mais competitivo em diversos setores, as empresas têm investido grandes quantias de recursos para atrair novos clientes, onde este valor é em média 25 vezes maior que investimentos na retenção dos mesmos (GALLO, 2014). Buscar novos clientes está diretamente ligado à estratégia das empresas de expansão do Market Share. Porém, entender as insatisfações dos clientes quando os mesmos rompem o relacionamento é vital na redução de custos e geração de crescimento sustentável. Durante o relacionamento com a empresa, os 
clientes costumam deixar dados importantes a respeito da sua insatisfação com o serviço prestado (KERAMATI; GHANEEI; MIRMOHAMMADI, 2016). Estes dados podem ser coletados por meio de indicadores de redução de interações ao longo do tempo, por dados textuais de feedbacks espontâneos, por meio de avaliações de satisfação como NPS, e também de reclamações no SAC ou em plataformas externas da empresa.

As reclamações formais representam conjuntos de dados importantes para entendimento da satisfação dos clientes (KERAMATI; GHANEEI; MIRMOHAMMADI, 2016). Capturar, processar e entender as reclamações possibilitam implementações de melhorias contínuas nos produtos e serviços elevando a satisfação e retenção dos clientes ((JOUNG et al., 2019); (LIU; WAN; SU, 2019); (SEZGEN; MASON; MAYER, 2019)). Em Yang et al. (2019), os autores usam dados de reclamações de chat para prever clientes propensos a escalar sua reclamação e direcionam para uma área especializada para tratamento de problemas complexos. Em Sousa et al. (2020), os autores usam dados do ReclameAQUI com técnicas de MT para encontrar dentro do conjunto de reclamações grandes tópicos de problemas no setor de telecomunicações, onde os resultados são apresentados por empresa e região geográfica. Em Sezgen, Mason e Mayer (2019), os autores utilizam MT para investigar quais são os atributos que mais impactam na satisfação de clientes do setor aéreo utilizando dados de avaliações coletados na plataforma TripAdvisor.

Dados de reclamações representam uma poderosa fonte para extração de conhecimento e melhorias na satisfação dos clientes. Nas próximas seções, os fundamentos necessários deste processo e os trabalhos relacionados serão apresentados.

\subsection{Mineração de textos}

Textos são caracterizados como dados não-estruturados, ou seja, não podem ser representados com uma estrutura rígida que foi previamente planejada para armazená-los. Os seres humanos utilizam textos como protocolo de comunicação e devido a isso, textos representam a maior quantidade de dados disponíveis. Grandes quantidades de textos podem ser encontradas em redes sociais, portais de notícias, livros, artigos, tutoriais, centrais de atendimento, e-mails, entre outros. Devido a sua natureza não padronizada, a variedade de línguas e a existência de ruídos, a extração de conhecimento destes dados é mais complexo quando comparado com dados estruturados ((MARCACINI, 2011); (REZENDE, 2003)).

A MT é uma instanciação da mineração de dados, e pode ser definida como um processo de extração de informações úteis a partir de documentos textuais escritos em linguagem natural (REZENDE, 2003). Essa extração é feita por meio de uma variedade de algoritmos estatísticos e de AM gerando aplicações práticas a partir da informação gerada (AGGARWAL, 2018a). Numerosas aplicações já existem no cotidiano da sociedade, entre elas os motores de busca da internet, filtros de spam, categorização e organização de documentos, sistemas de recomendação baseado em conteúdo, analise de opiniões e reclamações para tomada de decisão, sendo o ultimo 
o foco deste trabalho ((YANG et al., 2019); (LIU, 2012); (HABIMANA et al., 2020); (SEZGEN; MASON; MAYER, 2019); (PICIU et al., 2018)).

Este trabalho utiliza o processo de MT definido por Rezende (2003) (Figura 3) que contém 5 etapas genéricas aplicáveis a diversos tipos de problemas: Identificação do Problema, Pré-Processamento, Extração de Padrões, Pós-processamento e Utilização do Conhecimento.

Figura 3 - Processo de Mineração de Textos. Fonte: Rezende (2003)

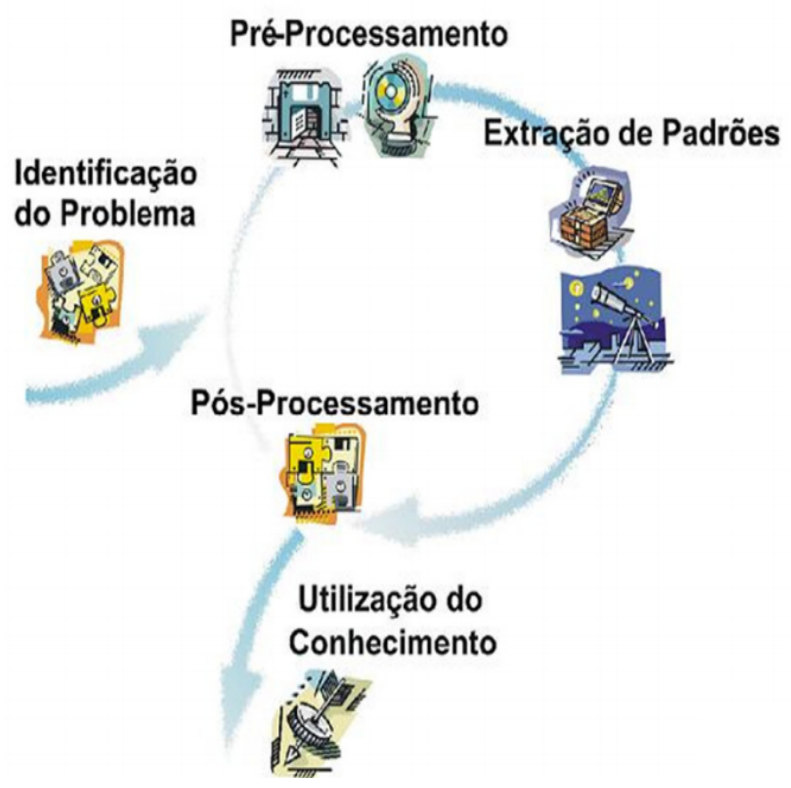

1. Identificação do Problema: com a ajuda de especialistas do domínio, nesta etapa ocorre a definição do problema e seu escopo que serão tratados com dados textuais. Questões a respeito dos dados devem ser esclarecidas, como: quais os conjuntos de dados disponíveis, seus atributos, sua periodicidade, qualidade, completude, privacidade dos dados e direitos de uso. Deve ser estabelecido o escopo de técnicas que podem ser empregadas baseando-se no critério de interpretabilidade, pois técnicas mais avançadas podem ter baixa interpretabilidade. E por último, quais as métricas serão utilizadas para avaliar a qualidade da solução.

2. Pré-Processamento: esta etapa diferencia a MT da mineração de dados tradicional, pois agrega um fator de complexidade devido a necessidade de estruturação dos textos. Podem ser empregados nesta etapa o tratamento de ruídos, remoção de stopwords, simplificação de termos com stemização ou lematização, remoção de caracteres inválidos, tratamento de dados pessoais ou sensíveis e normalização de frequência dos termos (AGGARWAL, 2018a). Após os tratamentos é necessário utilizar uma representação que será utilizada pelo algoritmo de extração de padrões, visto que não é possível apresentar o texto puro a estes algoritmos. A qualidade dos resultados dos algoritmos de extração de padrões é proporcional a qualidade da representação de textos e quais características eles conseguem capturar (ROSSI, 2016). 
3. Extração de Padrões: nesta etapa a representação dos textos é apresentada aos algoritmos de extração de padrões, por exemplo os algoritmos de AM. Esses algoritmos podem agrupar textos com mesmo tema, classificar textos baseando em rótulos previamente definidos, extrair regras de associação entre os textos, sumarização de textos e também executar regressão que diferencia da classificação pois a variável resposta é contínua (AGGARWAL, 2018a). A escolha do algoritmo está vinculada as necessidades e decisões estabelecidas na Identificação do problema.

4. Pós-Processamento: os resultados obtidos na extração de padrões são avaliados por meio de métricas definidas na etapa de identificação do problema. A métrica varia de acordo com o tipo de aplicação empregada, seja ela um agrupamento, associação, regressão ou classificação. Para problemas de classificação, como neste trabalho, as métricas mais comuns são derivadas da matriz de confusão: acurácia, precisão, revocação, f1-score, curva ROC (Receiver Operating Characteristic), AUC (Area under the ROC Curve), entre outras.

5. Utilização do Conhecimento: a utilização do conhecimento nesta etapa pode ser válido e útil se as etapas anteriores forem devidamente aplicadas. Como neste trabalho o conhecimento extraído é utilizado em processos de tomada de decisão, e devem ser constantemente monitorados para evitar que o algoritmo empregado perca a assertividade da métrica testada no pós-processamento. Nesse caso, o processo pode voltar para extração de padrões ou pré-processamento. Se houver mudança de escopo em relação ao objetivo, o processo deve retornar para a etapa de identificação do problema.

\subsection{Modelos de representação}

Os algoritmos de AM não são projetados para extrair padrões diretamente de dados não-estruturados de textos, sendo necessário transformar cada conjunto de dados textuais em uma representação numérica do seu conteúdo. Na etapa de pré-processamento, como descrito na Figura 3, é quando os dados são convertidos para o modelo de representação que será adotado. A escolha do modelo de representação é um passo fundamental dentro processo de MT, pois uma representação adequada reduz o consumo de recursos computacionais, o tempo de processamento e aumenta a capacidade de aprendizagem do algoritmo de AM ((SINOARA et al., 2019); (ROSSI, 2016)).

\subsubsection{Modelo Bag-of-Words}

O conceito de modelo de representação de textos no âmbito do espaço vetorial é popularmente conhecido como Bag-of-Words (BoW). Esta é uma representação esparsa e multidimensional usada na maioria das aplicações como uma técnica inicial de experimentação (AGGARWAL, 2018a). O método de construção do BoW inicializa varrendo todo o corpus de textos obtendo a 
lista de palavras ou termos distintos. A partir desta lista, o algoritmo constrói uma matriz em que cada termo é uma dimensão e cada registro é a representação de um texto dentro do corpus. Os valores da matriz são estritamente positivos e consideram a presença ou não dos termos nos textos quando binários. Os valores podem também representar a quantidade de cada termo presente em cada texto, sendo que nesse caso os valores são representados por inteiros discretos ((ROSSI, 2016; AGGARWAL, 2018a; SINOARA et al., 2019)).

Textos podem apresentar uma frequência muito alta de determinados termos que podem ser considerados outliers, gerando perdas na qualidade da representação. Técnicas de normalização dos valores podem ser empregadas para estabilizar e destacar termos dentro da representação. Entre essas técnicas, destaca-se o Term Frequency-inverse Document Frequency (TF-IDF). Conforme Equação 2.1, o TF-IDF é um indicador numérico que permite refletir na representação o quanto é importante um termo, dado o mesmo termo em todo o corpus. $\mathrm{O}$ valor do TF-IDF cresce proporcionalmente ao número de vezes que a palavra aparece no texto $t f(t, d)$ e é inversamente proporcional ao crescimento da mesma palavra no corpus $i d f(t, D)$ ((ROSSI, 2016; AGGARWAL, 2018a)).

$$
t f \_i d f(t, d, D)=t f(t, d) * i d f(t, D)
$$

BoW apresenta um bom custo benefício para representação de conteúdo dos documentos para utilização de algoritmos de AM em aplicações que a semântica não é relevante (SINOARA et al., 2019). Como vantagens dessa abordagem de representação destacam-se a simplicidade de implementação, a flexibilidade para ajustes e a explicabilidade da representação. Entre as suas principais limitações, destacam-se a incapacidade de capturar semântica das palavras que compõem os textos, além de gerar alta dimensionalidade e alta esparsidade que podem exigir uma quantidade significativa de recursos para o processamento.

\subsubsection{Modelos de linguagem}

Modelos de linguagem estatísticos ou somente modelos de linguagem tem como conceito estimar uma distribuição de probabilidade sobre sequências de palavras, modelando a probabilidade de uma palavra pertencer a sentença do idioma dado as palavras anteriores. (DAUPHIN et al., 2017). Dado uma sequencia de palavras $w_{1}, w_{2}, \cdots, w_{m}$, um modelo de linguagem calcula a probabilidade $P\left(w_{1}, w_{2}, \cdots, w_{m}\right)$ de pertencimento da sentença na língua (AGGARWAL, 2018a). Como exemplo, considere as seguintes sentenças:

- $\mathrm{s} 1$ = "o gato está dormindo";

- s2 = "está gato dormindo o";

Ao comparar a probabilidade das duas sentenças de ocorrerem na língua portuguesa, temos que $\mathrm{p}(\mathrm{s} 1)>\mathrm{p}(\mathrm{s} 2)$. Existem várias formas de calcular $P\left(w_{1}, w_{2}, \cdots, w_{m}\right)$, e a mais simples é o 
produtório da sequência da cadeia de palavras (AGGARWAL, 2018a):

$$
\begin{array}{r}
P\left(w_{1}, \ldots, w_{m}\right)=P\left(w_{1}\right) \times P\left(w_{1} \mid w_{2}\right) \times P\left(w_{3} \mid w_{1}, w_{2}\right) \times \cdots \times P\left(w_{m} \mid w_{1}, w_{2}, \cdots, w_{m-1}\right) \\
=\prod_{i=1}^{m} P\left(w_{i} \mid w_{1}, \cdots, w_{i-1}\right)
\end{array}
$$

Cada um dos termos $P\left(w_{i} \mid w_{1}, \ldots, w_{i-1}\right)$ precisam ser estimado com base nos dados. Isso é obtido expressando a probabilidade condicional com a regra de Bayes da seguinte forma:

$$
P\left(w_{i} \mid w_{1}, \cdots, w_{i-1}\right)=\frac{P\left(w_{1}, \cdots, w_{i}\right)}{P\left(w_{1}, \cdots, w_{i-1}\right)}=\frac{\operatorname{Count}\left(w_{1}, \cdots, w_{i}\right)}{\operatorname{Count}\left(w_{1}, \cdots, w_{i-1}\right)}
$$

No qual a função $\operatorname{Count}\left(w_{1}, \cdots, w_{i}\right)$ realiza as contagens das palavras das sentenças.

Esses modelos mostram-se efetivos e amplamente utilizado para aplicações de linguagem natural (DEVLIN et al., 2018), tal como aplicações de reconhecimento de fala (speech recognition), tradução (machine translation), marcação de parte da fala (Part of Speech (PoS) tagging), análise sintática (parsing), reconhecimento óptico de caracteres (Optical Character Recognition), reconhecimento de caligrafia (handwriting recognition), recuperação de informação (information retrieval). Nesta seção será apresentada uma visão geral sobre modelos de Transformers e a sua implementação mais popular atualmente, o Bidirectional Encoder Representations from Transformers (BERT).

\subsubsection{Modelos de word embeddings}

Embora representações como BoW sejam aplicáveis em muitos problemas, existem aplicações nas quais a representação sequencial de texto é necessária. Qualquer aplicação que requer uma compreensão semântica do texto necessita de uma representação que considere o texto como uma sequência de palavras, e não apenas a sua existência ou frequência como no modelo espaço vetorial (AGGARWAL, 2018a).

Para contornar a ausência de semântica dos termos e também dos documentos gerados por representações simples como BoW, novos modelos de linguagem baseados no modelo de espaço vetorial, conhecidos como Word Embedding Models foram construídos nos últimos anos. A base destes modelos é atribuir um vetor multidimensional de tamanho pré-definido a cada uma das palavras do corpus, sendo que palavras que ocorrem em contexto similares são consideradas similares por seus vetores, definido pela teoria da hipótese distribucional (HARRIS, 1954).

Entre vantagens na utilização de embeddings estão que palavras com formas e tempos verbais distintos, porém com semânticas parecidas, ficam próximas neste espaço multidimensional. É possível também a realização de operações matemáticas entre esses vetores e obter resultados clássicos como "rei está para rainha, assim como homem está para mulher" (AGGARWAL, 2018a). Como desvantagens, as word embeddings geradas por modelos livres de contexto geram uma mesma embbeding para uma mesma palavra que pode ter significados distintos. Por exemplo, 
nesses modelos, a word embbeding da palavra "banco" será a mesma, independente se ocorre no contexto de uma praça ou no contexto de serviços financeiros.

Os modelos de embeddings geralmente são construídos usando redes neurais conhecidas como autoencoders (AGGARWAL, 2018a), que possuem como entrada uma camada de tamanho $\mathrm{V}$, sendo $\mathrm{V}$ o domínio de termos possíveis, uma camada intermediária de tamanho $\mathrm{N}$, sendo $\mathrm{N}$ a dimensão das embeddings construídas e uma camada de saída com dimensão V novamente (Figura 4). O foco deste modelo é a utilização da camada intermediária de dimensão N, pois a mesma foi capaz de comprimir o espaço de termos altamente dimensional em um espaço vetorial pré-definido (LE; MIKOLOV, 2014).

Figura 4 - Autoencoder. Gerado pelo autor.

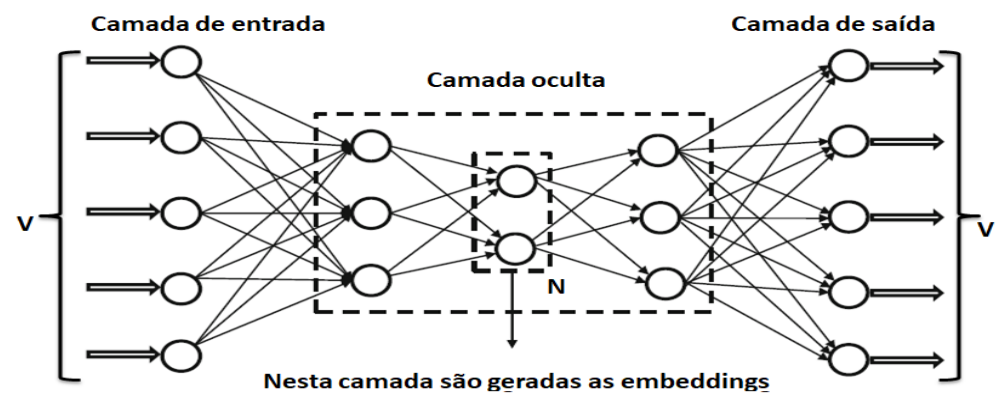

As implementações de embeddings disponibilizadas publicamente começaram com o pacote Word2Vec (Google) (MIKOLOV et al., 2013) que foi treinado por meio da base de dados do Google News Dataset utilizando 100 bilhões de tokens. O uso de embbedings como Word2Vec tem como vantagens a dimensionalidade fixa, pois os documentos são representados por um vetor de baixa dimensão pré-definido, e a incorporação de conhecimento externo oriundos de enormes corpus que são usados para gerar esses embeddings (SINOARA et al., 2019).

A partir da publicação do Word2Vec outras instituições passaram a disponibilizar seus modelos de word embeddings, como no caso do FastText (Facebook) (BOJANOWSKI et al., 2016), que utilizou 16 bilhões de tokens da wikipédia em seu treinamento base. O FastText apresenta como vantagem a capacidade de gerar embbedings de palavras que não participaram do treinamento, sendo este um fator de flexibilidade importante para aplicações textuais. Esta capacidade é possível porque o algoritmo utiliza uma abordagem baseada no skipgram, onde cada palavra é representada por um grupo de caracteres com tamanho $N$ ( $n$-gram). A embedding do termo desconhecido é gerado por aproximação dos $n$-grams conhecidos de outra palavras. Outras vantagens do FastText são a velocidade de treinamento em grandes conjuntos de textos e a não necessidade de pré-processamento ou supervisão no treinamento ((BOJANOWSKI et al., 2016); (JOULIN et al., 2016a)). 


\subsubsection{Modelos de Transformers}

Diferentemente de modelos de linguagem mais simples onde as palavras são apresentadas sequencialmente, os Transformers permitem que todas as palavras de uma mesma sequência sejam apresentadas simultaneamente e as embbedings são construídas simultaneamente no domínio da sentença. Essa diferença permite paralelização e alcançou um novo estado da arte em aplicações de tradução depois de ser treinado por apenas doze horas em oito GPUs P100 (VASWANI et al., 2017). Outra vantagem dos Transformers é a implementação do mecanismo de atenção no decoder, onde cada palavra possui um vetor de valores que indicam quais das outras palavras da sentença são mais relevantes para a palavra que está sendo processada. Uma característica importante nos Transformers é que uma mesma palavra em diferentes posições da sentença podem ter diferentes embeddings.

\subsubsection{Bidirectional Encoder Representations from Transformers (BERT)}

O Bidirectional Encoder Representations from Transformers (BERT) é uma evolução dos transformers, onde sua principal contribuição é a combinação do processamento bidirecional e dos Transformers. Esse método permite ao BERT ter vetores de atenção da esquerda para direita e da direita para esquerda para cada palavra, aproximando-se de como o cérebro humano constrói e interpreta as sentenças ((DEVLIN et al., 2018); (HABIMANA et al., 2020)).

O BERT utiliza o conceito de transferência de aprendizado, que refere-se ao processo onde um modelo treinado em um problema é usado de alguma forma em um segundo problema relacionado (MARCACINI et al., 2018). A abordagem de transferência de aprendizado é muito útil para aplicações com imagens, áudios e grandes corpus textuais pois são treinados em grandes bases de dados, durante dias ou semanas, usando matrizes de recursos de processamento exclusivos de algumas instituições, e posteriormente disponibilizado para uso geral. Em aprendizado profundo, a transferência de aprendizado é uma técnica pela qual um modelo neural complexo é primeiro treinado em um problema semelhante ao problema que está sendo resolvido. A partir do treinamento inicial, uma ou mais camadas do modelo treinado são ajustadas no problema de interesse.

O BERT é composto de multiplas camadas de codificadores Transformers (VASWANI et al., 2017). Existem duas arquiteturas do modelo, distintas pela quantidade de Transformers,

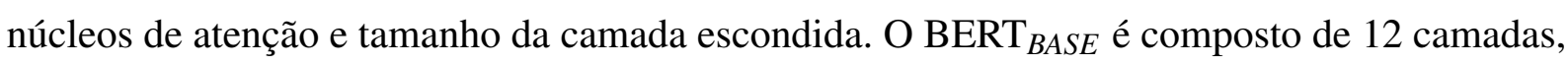
12 núcleos de atenção e tamanho 768 na camada escondida, enquanto que o BERT $_{L A R G E}$ possui 24 camadas, 16 núcleos de atenção e tamanho 1024 na camada escondida (SILVA, 2020).

O BERT é projetado para receber uma sentença ou várias sentenças concatenadas na entrada. Com a entrada, executa-se o tokenizador WordPieces (WU et al., 2016), que é um mecanismo que faz a separação dos tokens que podem ser palavras, parte de palavras ou pontuação. Após a tokenização, o BERT gera os vetores de embeddings que variam de acordo 
com a arquitetura BERT utilizada $\left(\mathrm{BERT}_{B A S E}\right.$ ou $\left.\mathrm{BERT}_{L A R G E}\right)$.

$\mathrm{Na}$ Figura 5 é ilustrada a representação de entrada do BERT para a frase "my dog is cute. he likes playing". O primeiro token de cada sequência é sempre um token de classificação especial [CLS] e para separar sentenças é utilizado o token [SEP]. Quando algum token não é encontrado no vocabulário do WordPieces, ele busca o token mais próximo para o prefixo e cria um novo token com prefixo \#\#. Em adição aos vetores de embeddings, é adicionado um vetor que indica qual sentença pertence o token e um outro vetor que indica qual é a posição dele dentro da sentença. A representação de entrada final do BERT é dada pela somatória dos vetores de word embeddings, de posição e de segmento.

Figura 5 - Representação de entrada do BERT. Fonte: Devlin et al. (2018)

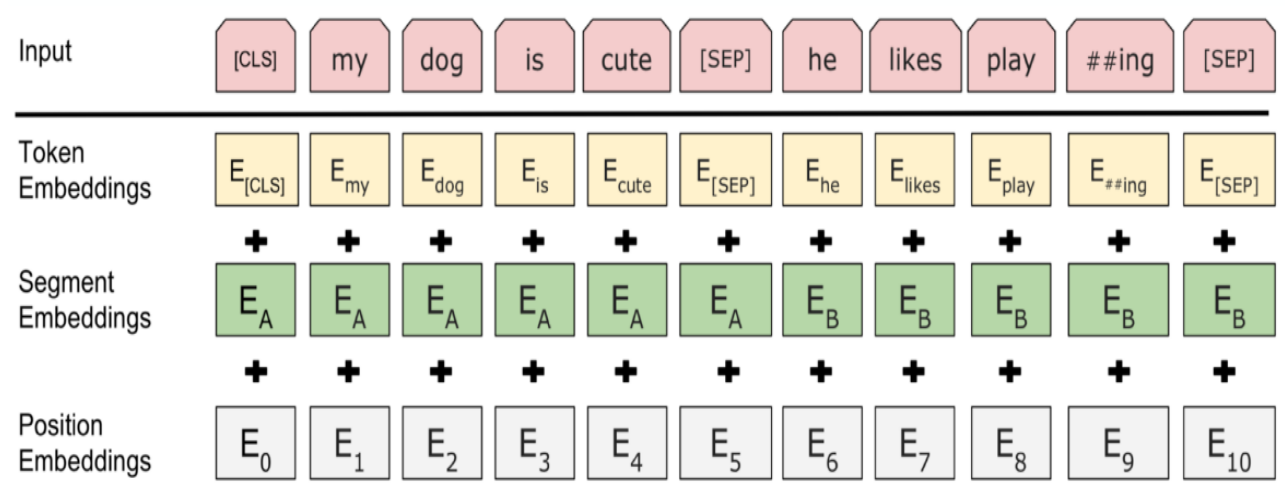

O treinamento do BERT é dividido em duas fases (Figura 6): pré-treinamento e refinamento (do inglês, Pre-Training e Fine-Tuning). No pré-treinamento o modelo é treinado em dados não categorizados em 2 diferentes tarefas: Masked Language Model (MLM) e Next Sentence Prediction (NSP). No MLM o BERT receberá como entrada uma sentença com tokens mascarados e fará a previsão destes tokens. Enquanto que no NSP o BERT retorna a probabilidade de uma sentença B vir imediatamente depois de uma sentença A. No refinamento, o BERT é inicializado com os parâmetros do pre-treinamento e apresentado para os dados categorizados, no qual suas últimas camadas de RNA Feed-forward com ativação Softmax são ajustadas (DEVLIN et al., 2018).

Modelos de linguagem pré-treinados como o BERT ficam cada vez mais lentos a medida que são treinados com mais conjuntos de dados. Nesse cenário os modelos de linguagem tem como limitante a capacidade de processamento que a plataforma onde eles são implantados pode processar. Nesse sentido o processamento em dispositivos com capacidade reduzida como smartphones pode ficar inviabilizada. A forma encontrada para redução dos modelos de linguagem e viabilizar o uso em um conjunto de aplicações com limitação de recursos computacionais é conhecida como destilação. A destilação é uma técnica utilizada para comprimir um grande modelo, chamado de professor, em um modelo menor, chamado de aluno. É uma técnica de compressão na qual um pequeno modelo é treinado para reproduzir o comportamento do modelo maior. Proposto por (SANH et al., 2019), o Distilled version of BERT (DistilBERT) é um modelo 
Figura 6 - Etapas de treinamento do BERT. Fonte: Devlin et al. (2018)

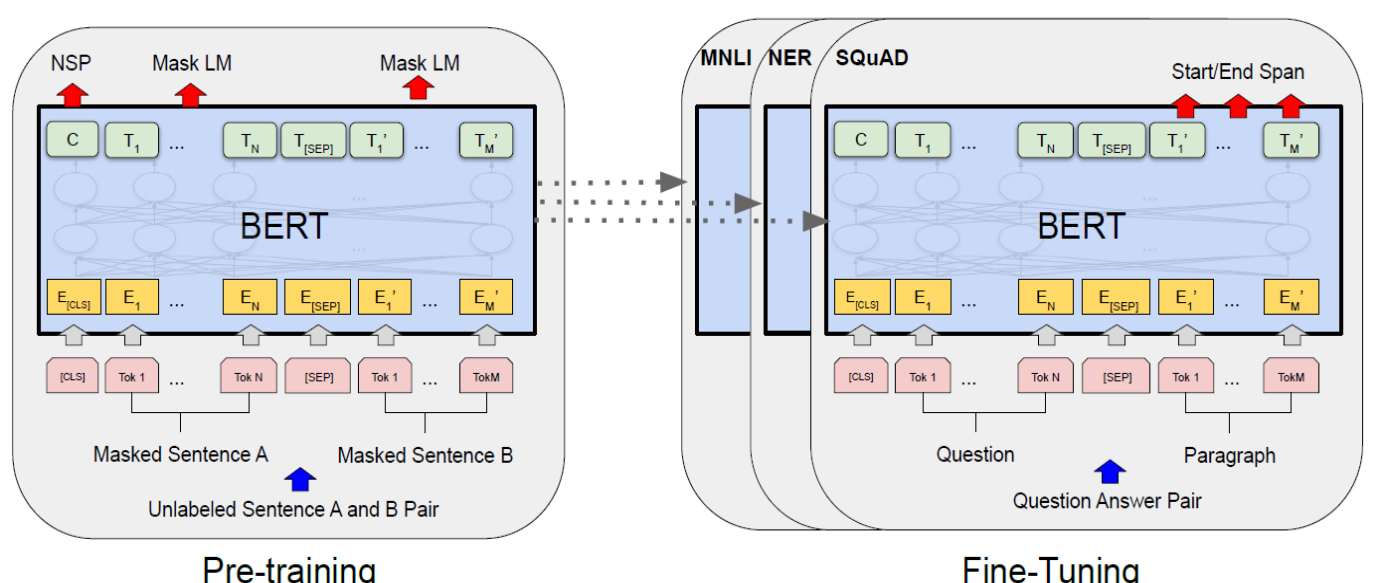

Pre-training

Fine-Tuning

de linguagem construído a partir da destilação do modelo BERT (DEVLIN et al., 2018). Este modelo conseguiu processar $60 \%$ mais rápido com redução de $40 \%$ do tamanho e mantendo 97\% das capacidades preditivas do BERT. É um modelo de linguagem de uso geral e uma opção interessante para aplicações de mercado.

\subsection{Aprendizado de máquina para mineração de textos}

Os algoritmos de AM são amplamente utilizados na etapa de extração de padrões, e de acordo com Rezende (2003), entre os algoritmos de AM mais populares estão: árvores de decisão, modelos lineares (Regressões Linear), modelos não lineares (Redes Neurais Artificiais), modelos baseados em exemplos K-Nearest Neighbor (KNN) e modelos probabilísticos como Naive Bayes. Nesta seção serão apresentadas 2 algoritmos de AM comuns em classificação de textos que serão empregados neste trabalho, Naive Bayes SVM (NBSVM) e as Redes Neurais Artificiais (RNA) Multilayer Perceptron (MLP).

\subsubsection{Naive Bayes SVM}

As variações de Naive Bayes (NB) e Support Vector Machine (SVM) são frequentemente utilizadas como modelos iniciais para classificação de textos. As performances destes classificadores podem variar consideravelmente dependendo da abordagem e da base de dados quando utilizados sozinhos (WANG; MANNING, 2012).

O modelo NBSVM proposto por Wang e Manning (2012) é processado em 2 etapas, sendo que na primeira é construída uma representação de modelo espaço vetorial nomeada de bag-of-features utilizando o cálculo do logaritmo das razões de probabilidades bayesianas. $\mathrm{O}$ objetivo do algoritmo nesta etapa é capturar, por exemplo, as probabilidades de uma palavra 
aparecer em uma classe positiva ou negativa. Na Equação 2.4 o vetor $r$ representa a saída do NB:

$$
r=\log \left(\frac{p /\|p\|_{1}}{q /\|q\|_{1}}\right)
$$

No qual os vetores $p$ e $q$ são definidos das seguinte maneira:

$$
p=\sum_{i: y^{(i)}=1} f^{(i)} ; q=\sum_{i: y^{(i)}=-1} f^{(i)}
$$

No qual: $f^{(i)}$ é a frequência de ocorrência de uma palavra na amostra $i$ e $y^{(i)}$ é a classe de $i$.

Com estas variáveis, a minimização do modelo SVM é descrita pela Equação 2.6:

$$
w^{T} w+C \sum_{i} \max \left(0,1-y^{(i)}\left(w^{T} f^{(i)}+b\right)\right)^{2}
$$

Uma modificação neste classificador ocorre na variável de entrada $x$ que é definida de modo diferente, calculada da seguinte forma:

$$
x^{(k)}=\tilde{f}^{(k)}=\hat{r} \circ f^{(k)}
$$

Em que: $\hat{r}$ e $f^{(k)}$ são os valores estimados de razão e de frequência para a população $k$ deduzidos do conjunto de treino.

Para adicionar mais robustez ao modelo, é feita uma interpolação nos vetores $w$ e $w^{\prime}$ :

$$
w^{\prime}=(1-\beta) \bar{w}+\beta w
$$

No qual: $w^{\prime}$ é a magnitude média de $w$ e $\beta$ é o parâmetro de interpolação.

Para problemas de classificação textual, a combinação do modelo de Naive Bayes com Support Vector Machine (NBSVM) apresentou resultados robustos em uma grande variedade de tarefas de classificação de texto em diferentes conjuntos de dados (LI et al., 2016; WANG; MANNING, 2012). Além disso, o NBSVM pode alcançar alto desempenho de classificação em conjuntos de treinamento pequenos com apenas 300 registros, além de conseguir escalar para grandes conjuntos de dados (RIEKERT; RIEKERT; KLEIN, 2021).

\subsubsection{Multilayer Perceptron}

RNA é uma classe de métodos de AM inspirados na biologia dos neurônios. Os primeiras trabalhos usando métodos inspirados nos neurônios começaram nos anos 40, porém a proposta do algoritmo perceptron (ROSENBLATT, 1958) é considerado a pedra fundamental das redes neurais, o que causou um entusiasmo inicial sobre as perspectivas da inteligência artificial (AGGARWAL, 2018b). As RNA tem sido amplamente aplicadas em problemas de classificação de textos, principalmente por meio dos conceitos que compreendem o aprendizado profundo, 
onde as redes possuem múltiplas camadas, possuem formatos diferenciados de acordo com o tipo de aprendizado e podem transferir conhecimento entre elas (AGGARWAL, 2018b).

O MLP é a implementação mais comum de RNA e se enquadra na categoria de feedforward, sendo que o fluxo de informações que geram o aprendizado ocorrem do inicio para o fim da rede sem gerar ciclos. Uma MLP consiste de pelo menos 3 camadas de neurônios perceptron, sendo uma camada de entrada, uma camada oculta e uma camada de saída. Exceto para os nós de entrada que tem função apenas de propagar os dados, os neurônios utilizam uma função de ativação não-linear que recebe como entrada os valores da camada anterior ponderados por um vetor de pesos exclusivo de cada neurônio (AGGARWAL, 2018a).

O MLP utiliza o backpropagation como algoritmo de treinamento, onde o erro na saída da RNA é usado para ajustar os pesos dos vetores das camadas de neurônios anteriores. Esses ajustes ocorrem partindo da ultima camada até a camada de entrada, onde a retropropagação do erro segue ajustando os pesos das camadas de neurônios até a camada inicial. O Gradiente Descendente combinado com uma taxa de aprendizado é o método empregado de otimização dos pesos (AGGARWAL, 2018b).

\subsection{Trabalhos relacionados}

Nesta seção é feito um breve resumo de alguns trabalhos que aplicaram MT em problemas com dados de satisfação ou reclamações de consumidores.

Em Yang et al. (2019), os autores têm como objetivo detectar a intenção do cliente de escalar sua reclamação ao órgão regulador. Como contexto, o trabalho usa dados de texto de chat da chinesa jd.com que é o principal e-commerce no país. A utilização do conhecimento obtido foi testado em uma ferramenta que monitora chats de reclamações de clientes em tempo real e direciona os clientes propensos a escalar sua reclamação para uma área especializada para tratamento de problemas complexos. Foi utilizado como proposta um modelo híbrido de redes neurais com variáveis projetadas manualmente.

Em Sezgen, Mason e Mayer (2019), os autores definem um processo baseado em Latent Semantic Analysis (LSA) para minerar mais de 5 mil avaliações da plataforma TripAdvisor e diferenciar os fatores de (in)satisfação de clientes do setor aéreo. Os resultados foram segmentados por classe de cabine e modelo de negócios, e são usados para direcionar as companhias aéreas nos seus processos de melhoria contínua nos principais motivadores que impactam a satisfação de seus clientes.

Em Liu, Wan e Su (2019), os autores propõem um método para detecção de expectativas dos clientes, pois quando suas expectativas são atendidas, a satisfação aumenta. As expectativas foram categorizadas em resolução de problemas, compensação financeira e compensação psicológica. Os dados foram obtidos por meio de uma plataforma de reclamações automobilísticas. 
Foram testados 8 tipos de classificadores de AM em cenários de representação de textos usando BoW com TF-IDF, embbedings Word2vec e GloVe.

Em Krishna et al. (2019), os autores aplicaram técnicas de AM para classificação de sentimentos em dados de reclamações de 4 bancos indianos. Analises foram feitas com e sem técnicas de pré-processamento de textos. As representações de textos avaliadas foram documentterm matrix (DTM) do tipo BoW com TF-IDF, Word2Vec e Linguistic Inquiry and Word Count (LIWC). Os resultados das abordagens de representação LIWC com Random Forest e Naive Bayes apresentaram os melhores resultados.

Em Joung et al. (2019), os autores exploram a aplicação de MT em dados de reclamações de clientes de empresas de ar de condicionado coreanas para identificar as verdadeiras necessidades dos clientes usando o método Outcome-Driven Innovation (ODI) em combinação com analise por agrupamentos hierárquicos. As necessidades levantadas serviram para direcionar o desenvolvimento de novas funcionalidades dos produtos com intuito de aumentar a atratividade dos mesmos e a satisfação dos clientes.

Em Iglesias (2020), os autores exploraram a contribuição de MT em um SAC de uma empresa do setor automobilístico. Um processo de mineração é apresentado desde os dados brutos até na extração de conhecimento. Os algoritmos Naive Bayes, Sequential minimal optimization (SMO) e árvores de decisão foram empregados na mensuração da (in)satisfação dos consumidores dado o lançamento de um novo modelo de carro.

Em Sousa et al. (2020), os autores usam dados do ReclameAQUI com técnicas de MT para encontrar dentro do conjunto de reclamações grandes conjuntos de problemas no setor de telecomunicações, sendo que os resultados são apresentados por empresa e região geográfica. A principal contribuição do trabalho está na proposta de uma abordagem que auxilia no planejamento estratégico das empresas, levando em consideração situações reportadas pelos consumidores.

Na Tabela 1 é apresentado um resumo dos trabalhos citados. Na coluna Consumidor é apresentado uma divisão pelo tipo de dado explorado: avaliação e/ou reclamação de produtos ou serviços, sendo que os trabalhos que utilizam ambos geralmente separam eles. A coluna Extração de padrões mostra que tipo de técnicas foram empregadas. A coluna Técnicas estatísticas são geralmente técnicas de analises algébricas que não se enquadram em AM ou Aprendizado profundo. Na utilização do conhecimento a coluna análise de sentimentos indica que o trabalho focou apenas nesse tema sem abordar a resolução de conflitos ou na extração de necessidades dos clientes.

Os trabalhos relacionados possuem aplicações práticas com dados de satisfação ou reclamações de consumidores e os mesmos não exploraram o uso de modelos de linguagem. $\mathrm{O}$ presente trabalho visa explorar o modelo de linguagem BERT em comparação com o modelo NBSVM e as embeddings livres de contexto FastText com MLP. Esses cenários comparativos 
Tabela 1 - Comparativo entre trabalhos relacionados

\begin{tabular}{|c|c|c|c|c|c|c|c|c|}
\hline & \multicolumn{2}{|c|}{ Consumidor } & \multicolumn{3}{|c|}{ Extração de padrões } & \multicolumn{3}{|c|}{ Utilização do conhecimento } \\
\hline Trabalho & Avaliação & Reclamação & $\mathrm{AM}$ & $\begin{array}{c}\text { Técnicas } \\
\text { estatisticas }\end{array}$ & $\begin{array}{l}\text { Modelos de } \\
\text { Linguagem }\end{array}$ & $\begin{array}{c}\text { Analise de } \\
\text { sentimentos }\end{array}$ & $\begin{array}{l}\text { Resolução } \\
\text { de conflitos }\end{array}$ & $\begin{array}{c}\text { Necessidades } \\
\text { de clientes }\end{array}$ \\
\hline [Yang et al. 2019] & & $\mathrm{X}$ & $\mathrm{X}$ & & & & $\mathrm{X}$ & \\
\hline [Sezgen et al. 2019] & $\mathrm{X}$ & $\mathrm{X}$ & & $\mathrm{X}$ & & & & $\mathrm{X}$ \\
\hline [Liu et al. 2019] & & $\mathrm{X}$ & $\mathrm{X}$ & & & & $\mathrm{X}$ & $\mathrm{X}$ \\
\hline [Krishna et al. 2019] & & $\mathrm{X}$ & $\mathrm{X}$ & & & $\mathrm{X}$ & & \\
\hline [Joung et al. 2019] & & $\mathrm{X}$ & $\mathrm{X}$ & & & & & $\mathrm{X}$ \\
\hline [Iglesias 2020] & $\mathrm{X}$ & $\mathrm{X}$ & $\mathrm{X}$ & $\mathrm{X}$ & & $\mathrm{X}$ & & \\
\hline [Sousa et al. 2020] & & $\mathrm{X}$ & & $\mathrm{X}$ & & & & $\mathrm{X}$ \\
\hline
\end{tabular}

visam entender a aplicabilidade de modelos simples e complexos nos cenários reais de previsão de resolutividade de reclamações de clientes, simulando a aplicação dos modelos no processo de atendimento das empresas.

Utilizando como base os fundamentos e referências bibliográficas apresentados neste capítulo, no próximo capítulo será apresentado uma proposta metodológica de aplicação de MT para minimizar o risco de insatisfação de clientes em um fluxo de atendimento de reclamações. 



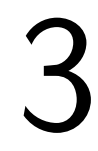

\section{ATENDIMENTO DE RECLAMAÇÕES DE CLIENTES USANDO MINERAÇÃO DE TEXTOS}

Este capítulo tem como objetivo propor uma metodologia de desenvolvimento de modelos de MT para triagem de reclamações dado a probabilidade de resolutividade das mesmas. É proposto também um macro processo de atendimento capaz de aplicar esses modelos e gerar valor na experiência do cliente. Esta metodologia apresenta a linha de raciocínio do trabalho, sendo que seu embasamento é dado pelo Capítulo 2 e os resultados da avaliação experimental serão apresentados no Capítulo 4.

\subsection{Mineração de textos em reclamações de clientes}

A MT pode ser definida como um processo de extração de informações úteis a partir de documentos textuais escritos em linguagem natural (REZENDE, 2003). Este processamento é feito por meio de uma variedade de algoritmos estatísticos e de AM gerando aplicações práticas a partir da informação gerada (AGGARWAL, 2018a). A metodologia de desenvolvimento dos modelos aplicados na triagem de reclamações empregadas neste trabalho, que foi detalhada no Capítulo 2, segue o framework descrito por Rezende (2003) (Figura 3), que contém 5 etapas genéricas aplicáveis a diversos tipos de problemas: Identificação do Problema, PréProcessamento, Extração de Padrões, Pós-processamento e Utilização do Conhecimento. Na Figura 7 são apresentados os processos necessários no desenvolvimento em cada uma das etapas a partir da instancialização do framework para mineração de textos em dados de reclamações de clientes. Este fluxo serve como um guia macro para entendimento e direcionamento, sendo que cada um dos processos serão descritos nas sub-sessões seguintes. 
Figura 7 - Processo de MT instanciado. Gerado pelo autor.

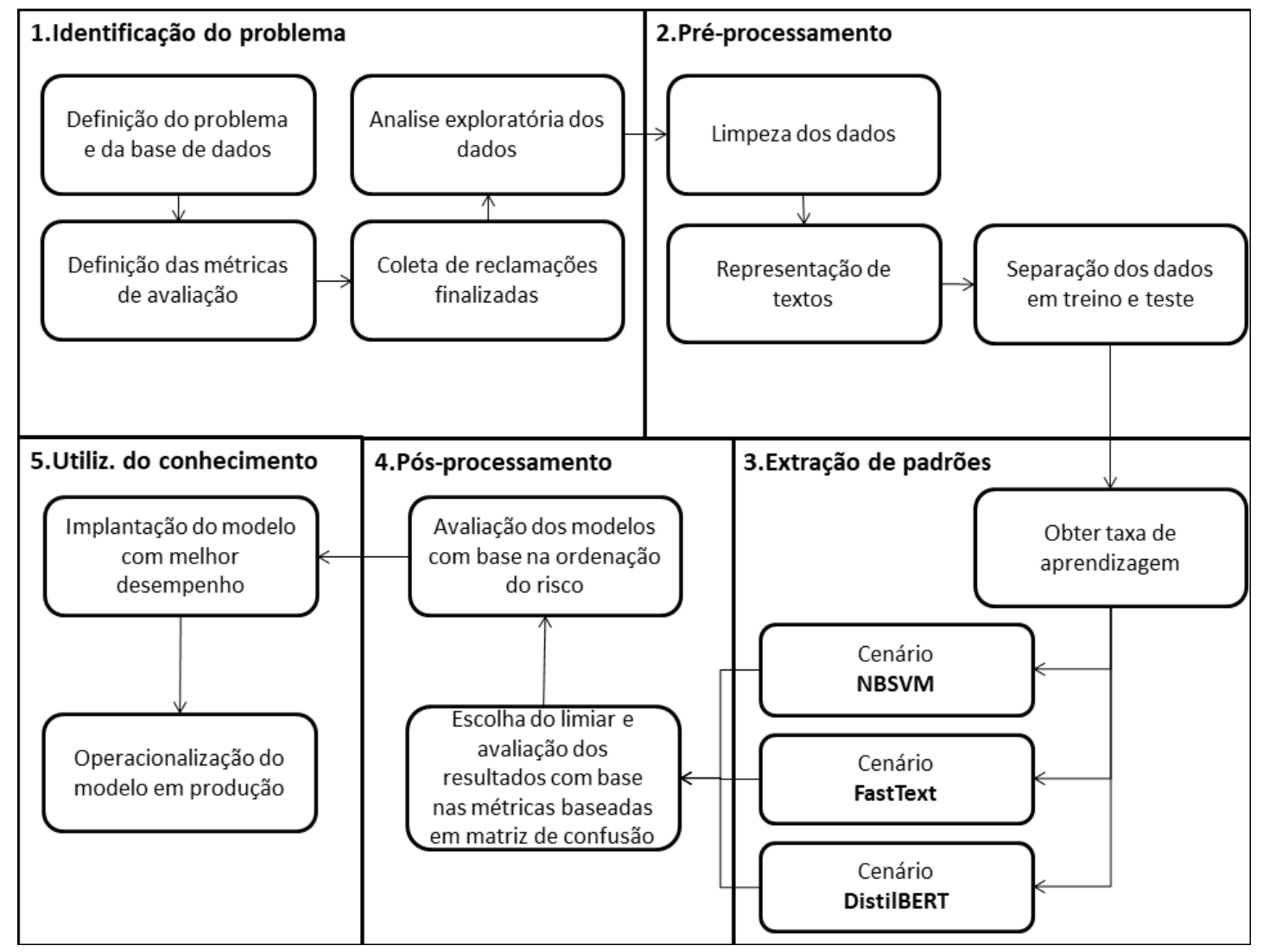

\subsubsection{Problema de reclamações de clientes}

As empresas gastam quantidade considerável de seu orçamento para gerir o atendimento de reclamações de seus clientes, e mesmo assim veem sua reputação despencar em grande parte dos casos. As áreas responsáveis pelo atendimento são divididas em níveis, e quanto maior o nível, mais capacidades a área possui para resolver o conflito. A comunicação com o cliente é apenas a interface do processo de atendimento, e geralmente uma reclamação demanda o acionamento de várias áreas internas da empresa. Esse fluxo de acionamento interno quando não otimizado gera alto custo de tempo e dinheiro, pois uma reclamação mal distribuída pode correr várias áreas que não possuem papel de resolução ou alçada para o mesmo.

Quando o processo de atendimento de reclamações das empresas possuem problemas, são nas plataformas de ODR que as falhas ficam mais evidentes e é onde as empresas veem sua imagem perder mais valor. Muitas são as plataformas de ODR disponíveis, e elas tem como função arbitrar o processo de negociação entre consumidor e empresa provendo a tecnologia necessária. O processo parte de uma insatisfação sentida pelo consumidor que é descrito por meio da narrativa da reclamação. Durante o processo de atendimento está em jogo não somente a resolução do conflito, mas também a imagem da empresa, que tem como objetivo mostrar por meio dos indicadores da plataforma de ODR que ela se preocupa com a satisfação dos seus clientes. 


\subsubsection{Coleta de dados de reclamações}

Devido a relevância da plataforma no cenário brasileiro, os fatores de engajamento, o fluxo de reclamações bem definido, a qualidade e a diversidade dos dados, este trabalho optou por obter os dados da plataforma ReclameAQUI. Na Figura 8 são destacados os dados coletados na plataforma. As variáveis obtidas foram "Título da reclamação", "Empresa reclamada", "Narrativa da reclamação"e "Narrativa da resposta", sendo que as duas últimas são as variáveis textuais que foram utilizadas como variáveis independentes neste trabalho. Como variável dependente foi coletada a variável "O problema foi resolvido?", que indica se cliente entende que a reclamação foi resolvida ou não.

Figura 8 - Dados coletados no ReclameAQUI. Fonte: ReclameAQUI (2021)

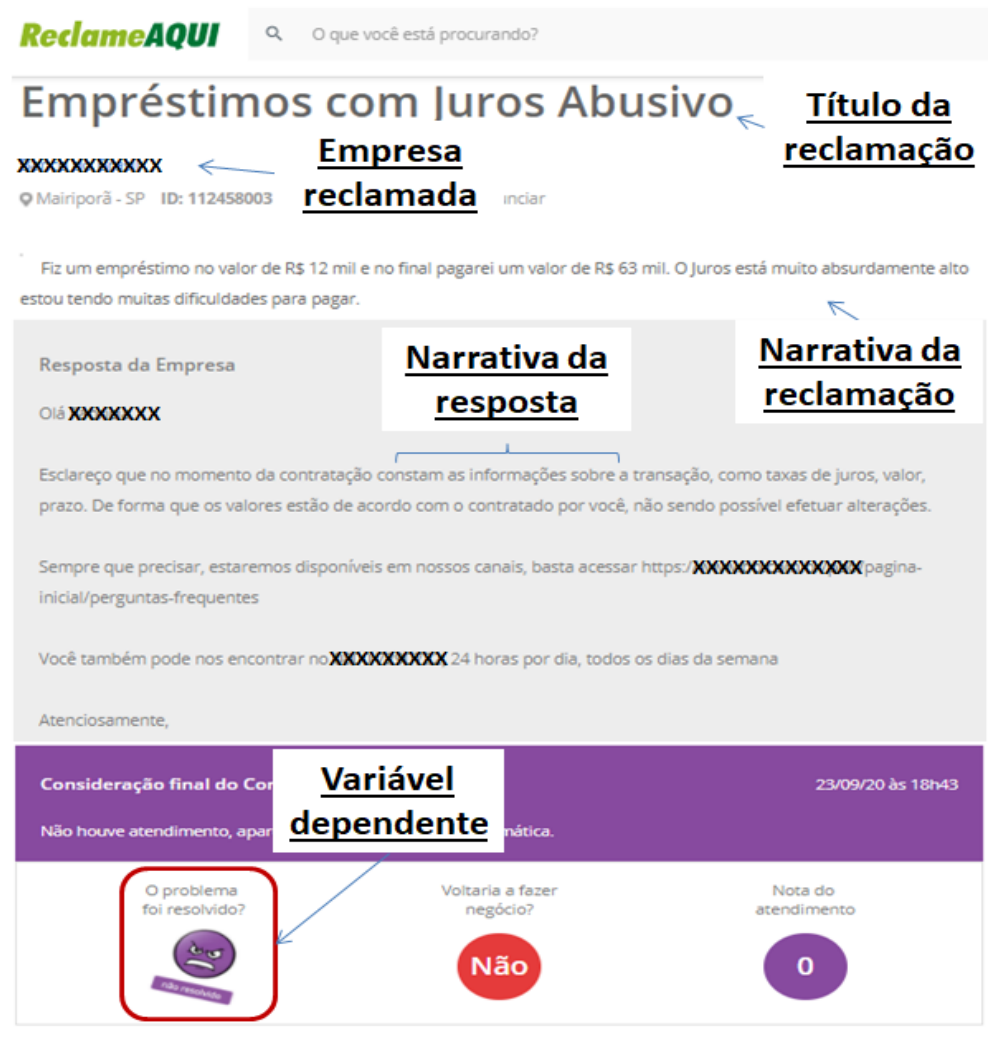

Para capturar os dados a serem utilizados, um trabalho de pré-seleção entre os principais bancos brasileiros foi feito. Esta análise visou obter a maior variabilidade de respostas, portanto com foco nas narrativas das respostas que apresentam a solução do problema do cliente detalhadamente. A variabilidade textual da resposta da empresa é imprescindível no processo de aprendizagem e generalização.

\subsubsection{Análise de similaridade das respostas}

Após as descritivas dos dados de reclamações dos 4 maiores bancos brasileiros na plataforma ReclameAQUI, percebeu-se que em alguns bancos a resposta da reclamação estava padronizada. Isso significa que a resolução do problema não foi necessariamente descrito na 
plataforma, e a resolução real foi comunicada diretamente ao cliente por meio de um outro canal de atendimento. Na Figura 9 são mostrados exemplos de respostas padronizadas (com pré-processamento) que não descrevem a real resolução do problema.

Figura 9 - Exemplos de atendimento por resposta padronizada. Gerado pelo autor.

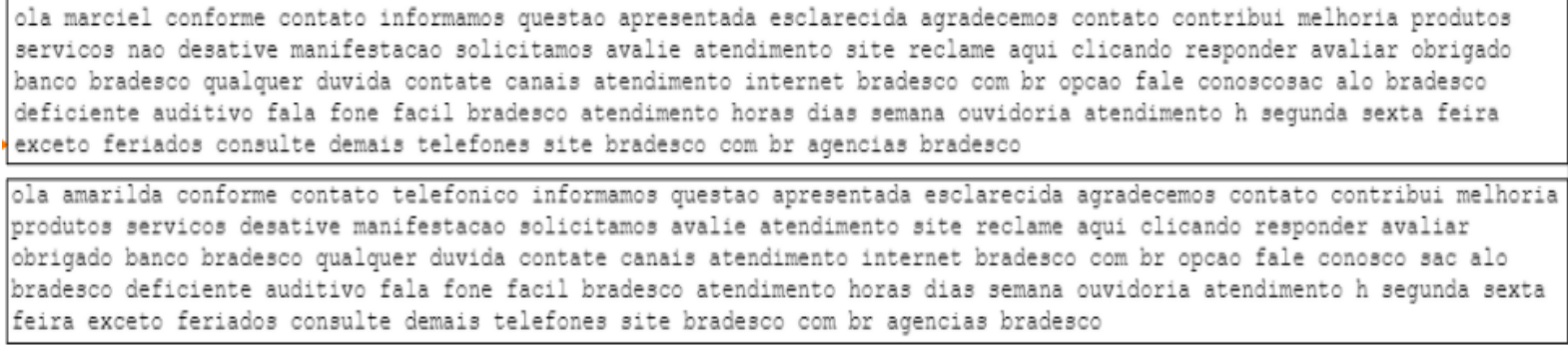

ola amarilda conforme contato telefonico informamos questao apresentada esclarecida agradecemos contato contribui melhoria produtos servicos desative manifestacao solicitamos avalie atendimento site reclame aqui clicando responder avaliar obrigado banco bradesco qualquer duvida contate canais atendimento internet bradesco com br opcao fale conosco sac alo bradesco deficiente auditivo fala fone facil bradesco atendimento horas dias semana ouvidoria atendimento h segunda sext feira exceto feriados consulte demais telefones site bradesco com br agencias bradesco

Como a variabilidade textual da resposta da empresa é imprescindível no processo de aprendizagem e generalização, foi necessário escolher dentre os bancos aquele com maior variabilidade de respostas. Para executar esta análise todas as respostas foram convertidas em embeddings livres de contexto e a partir disso foi calculado o centroide para cada uma das empresas. Dado o centroide, foi calculada a distancia cosseno (Equação 3.1) para todas as respostas.

$$
\operatorname{cosseno}(\Theta)=\frac{A \cdot B}{\|A\|\|B\|}=\frac{\sum_{i=1}^{n} A_{i} B_{i}}{\sqrt{\sum_{i=1}^{n} A_{i}^{2}} \sqrt{\sum_{i=1}^{n} B_{i}^{2}}}
$$

Com todas as distancias calculadas em relação ao centroide, foi empregada para visualização uma redução de dimensionalidade por meio da análise de componentes principais. $\mathrm{Na}$ Figura 10 são apresentadas as distribuições das distancias em relação o centroide dos bancos B1, B2, B3 e B4.

Figura 10 - Distribuição das respostas em relação ao centroide. Gerado pelo autor.
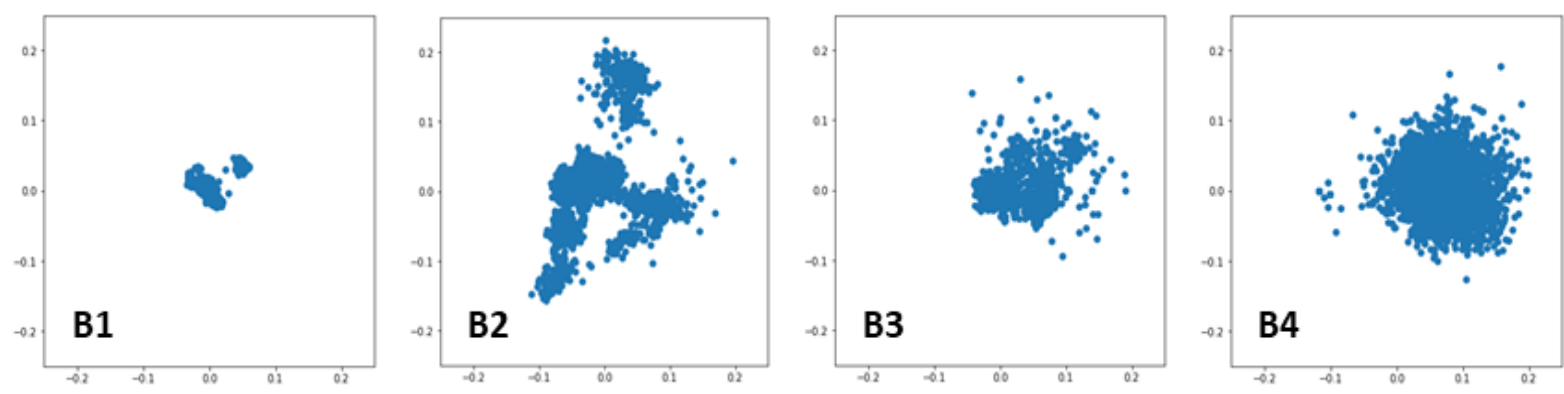

As conclusões da análise foram: o B1 atende por um grupo de resposta padronizada, o B2 responde por pelo menos 3 grupos de respostas padronizadas, o B3 varia entre respostas padronizadas e respostas de resoluções e o B4 é um banco que formaliza as resoluções nas respostas da plataforma. Um ponto importante a ser esclarecido é que neste trabalho não será declarado o nome do banco que foi escolhido por questão de privacidade e todo momento que 
necessitar especificar a empresa, ela será definida como B4. É importante ressaltar que após o emprego desta técnica, uma inspeção visual nas respostas foi feita para garantir que realmente as respostas estavam descrevendo a solução adotada pela empresa.

\subsubsection{Pré-processamento de reclamações}

A etapa de pré-processamento diferencia a MT da mineração de dados tradicional, pois agrega um fator de complexidade na estruturação e representação dos dados. A inteligência humana possui a capacidade de ler a codificação textual, interpretar e tomar decisões sobre elas naturalmente, porém para os algoritmos de AM é necessário uma re-codificação em uma estrutura de representação numérica. Essas estruturas de dados são conhecidas como modelos de representação de textos, e foram apresentados na seção 2.3.1.

A etapa de limpeza dos dados antes da representação é de suma importância, pois evita que documentos, palavras e caracteres indesejados participem da representação e consequentemente gerem ruído no treinamento. Nesta etapa será empregado a normalização dos dados em ascii minusculo, remoção de múltiplos espaçamentos, adequação de pontuações e espaçamentos e remoção das reclamações com menos de 40 caracteres. Alguns exemplos de como será a limpeza dos textos das reclamações são mostrados na Figura 11.

Figura 11 - Exemplos de limpeza dos dados. Gerado pelo autor.

\begin{tabular}{cr} 
reclamacao & reclamacao_cleanned \\
\hline Fiz um acordo para o parcelamento de uma dívid... & fiz acordo parcelamento divida acordo fora u... \\
O pacote se serviços está disponível 1 TED men ... & pacote servicos disponivel 1 ted mensal porem... \\
Caros, abri uma conta pelo aplicativo há cerca .... & caros abri conta aplicativo cerca 5 meses des...
\end{tabular}

Para obter o modelo de representação usado em cada um dos modelos é necessário primeiramente separar os textos em tokens. Os tokens são unidades de dados que podem compreender partes de palavras, palavras inteiras ou até mesmo conjunto de palavras. Estas unidades são definidas pelo tokenizador do algoritmo de AM. Nas representações a serem usadas pelo NBSVM e FastText, os tokens serão separados pelo caracter de espaço, enquanto que no DistilBERT o tokenizer é específico do modelo de linguagem. De acordo com Sanh et al. (2019), o DistilBERT consegue processar até 512 tokens por documento e devido essa restrição será utilizada a estratégia head and tail, definida como a melhor solução por Sun et al. (2019). Seguindo a estratégia head and tail as reclamações que superaram 512 tokens são reduzidas considerando os 128 tokens do inicio e 382 tokens do final.

Serão empregados 2 tipos de pré-processamento para montagem das representações, sendo um padrão para os modelos NBSVM e FastText, e um pré-processamento especial para o DistilBERT que se diferencia na etapa de geração das embeddings. Todos os métodos de 
pré-processamento a serem empregados criam um vetor de 512 tokens para cada documento, no qual cada posição indica o ID da palavra naquela posição. Além disso, os algoritmos possuem uma estrutura auxiliar que mapeia o ID do token para a estrutura representada, que neste trabalho são Naive Bayes log count ratios para o NBSVM, embeddings livre de contexto para o FastText e embeddings contextuais para o DistilBERT. Além disso foi definido também a utilização de 1-gram, ou seja, os tokens são compostos por palavras simples.

\subsubsection{Extração de padrões}

A etapa de extração de padrões consiste da aplicação dos algoritmos de AM escolhidos nas tarefas de generalização do conhecimento. O conhecimento é uma representação construída pelo algoritmo de AM no momento do treinamento. Vários métodos de treinamento podem ser aplicados, sendo os mais conhecidos os métodos de validação cruzada:

- Holdout: este é método mais comum e consiste em dividir o conjunto total de dados em dois subconjuntos mutuamente exclusivos, um para treinamento e outro para teste.

- $k$-fold: o método consiste em dividir os dados de treinamento em $k$ partes, usando $k-1$ partes para treino e a parte remanescente para teste, fazendo isso $k$ vezes. Em cada uma das $k$ vezes, testa-se o modelo com um fold diferente calculando a métrica escolhida para avaliação do modelo. Ao final do processo, obtém-se $k$ medidas da métrica de avaliação escolhida, com as quais geralmente utilizamos a média e o desvio-padrão.

- Leave one out: é um caso específico do $k$-fold, com $k$ igual ao número total de dados $N$. Neste método, separa-se um único elemento para teste e treina-se com o restante dos dados. O resultado é calculado como média dos resultados parciais de todas as execuções. Devido a excessiva quantidade de execuções de treino o método possui um custo elevado de processamento e costuma ser pouco empregado.

Os algoritmos de AM empregados em problemas de classificação de texto costumam ter um custo computacional elevado quando comparamos com dados estruturados. Nesse cenário, o método de validação empregado neste trabalho será o Holdout devido a sua simplicidade e ao seu custo computacional reduzido perante os demais métodos.

Os experimentos serão construídos com linguagem de programação Python utilizando a biblioteca ktrain (MAIYA, 2020) que empacota e simplifica a utilização da biblioteca Keras (CHOLLET et al., 2015) que implementa entre outras, os algoritmos testados neste trabalho. O processamento será por meio da plataforma Google Colaboratory (GOOGLE, 2021), que disponibiliza gratuitamente recursos computacionais para processamento de projetos de ciência de dados. Os modelos de representação de textos e técnicas de AM foram testadas em 3 arquiteturas distintas de modelos de classificação de textos: 
1. Naive Bayes log count ratios com classificador SVM (NBSVM): proposto por Wang e Manning (2012), a solução utiliza como representação a probabilidade de cada token aparecer em uma determinada classe (positivo ou negativo) e é computado o logaritmo da razão dessas probabilidades. Estes vetores são utilizados por um classificador SVM com kernel linear ou uma regressão logística. Apesar de sua simplicidade, o modelo NBSVM demonstra ser rápido e eficaz em uma ampla variedade de conjuntos de dados de classificação de texto diferentes.

2. Embeddings livres de contexto FastText com MLP (FastText): proposto por Bojanowski et al. (2016), a solução proposta utiliza como representação as embeddings livres de contexto da linguagem utilizada e uma rede neural recorrente com unidades Long Short Term Memory (LSTM) como classificador. Esta solução tem como principais características a capacidade de gerar embeddings para tokens não conhecidos e a boa performance computacional (JOULIN et al., 2016b).

3. DistilBERT: é um modelo de linguagem construído utilizando a arquitetura do BERT (DEVLIN et al., 2018) com redução em 40\% do tamanho, porém mantendo $97 \%$ das capacidades preditivas (SANH et al., 2019). Como modelo de linguagem é capaz de transferir o aprendizado gerado na sua construção ajustando suas embeddings ao contexto de classificação do domínio aplicado.

Um passo importante na etapa de aprendizagem para os modelos implementados no ktrain é a escolha da taxa de aprendizagem. As taxas de aprendizagem serão obtidas por meio da função find learning rate que executa o treinamento por até 100 épocas ou até a convergência, o que ocorrer primeiro, para sugerir uma taxa de aprendizagem adequada. A evolução do estimador durante as épocas é mostrado na Figura 12 para os modelos 1, 2 e 3 respectivamente.

Figura 12 - Evolução da taxa de aprendizagem para os modelos 1, 2 e 3. Gerado pelo autor.
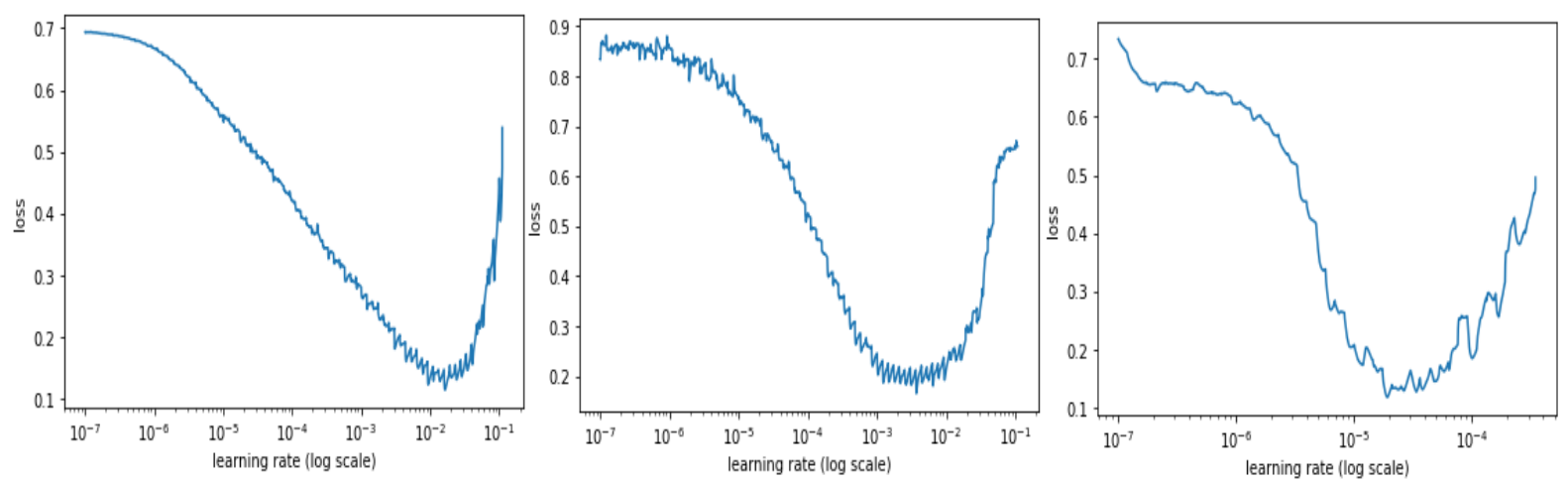

A taxa de aprendizagem para cada modelo é escolhida no gráfico como sendo um valor próximo do vale, porém antes do mínimo. Para o treinamento dos modelos as taxas de aprendizagem usadas inicialmente para os modelos 1, 2 e 3 foram respectivamente: 1e-2, 1e-3 e 5e-5. A função autofit foi empregada no treinamento dos modelos, sendo que ela parte da 
taxa de aprendizagem pré-definida e ajusta a mesma evitando aprendizados indesejados como underfitting e overfitting.

\subsubsection{Pós-processamento}

Na etapa de pós-processamento, o processo de aprendizagem deve avaliar se os resultados obtidos na extração de padrões são satisfatórios para aplicação no problema. Para responder essa pergunta são utilizadas as métricas definidas na etapa de identificação do problema. Neste trabalho utilizaremos um conjunto de métricas derivadas da matriz de confusão, que é uma tabela que mostra as frequências de classificação para cada classe do modelo conforme Tabela 2.

Tabela 2 - Matriz de confusão

\begin{tabular}{|l|l|c|c|}
\multicolumn{2}{c|}{} & \multicolumn{2}{c|}{ Valor Predito } \\
\hline Real & Sim & Verdadeiro Positivo (VP) & Falso Negativo (FN) \\
\cline { 3 - 4 } & Não & Falso Positivo (FP) & Verdadeiro Negativo (VN) \\
\hline
\end{tabular}

- Verdadeiro positivo (VP): ocorre quando no conjunto real, a classe que estamos buscando foi prevista corretamente. Por exemplo, quando a reclamação não foi resolvida e o modelo previu corretamente este evento.

- Falso negativo (FN): ocorre quando no conjunto real, a classe que não estamos buscando prever foi prevista incorretamente. Por exemplo, quando a reclamação não foi resolvida e o modelo previu incorretamente que ela foi resolvida.

- Falso positivo (FP): ocorre quando no conjunto real, a classe que estamos buscando prever foi prevista incorretamente. Exemplo: quando a reclamação foi resolvida, mas o modelo disse que ela não foi.

- Verdadeiro negativo (VN): ocorre quando no conjunto real, a classe que não estamos buscando prever foi prevista corretamente. Exemplo: a reclamação foi resolvida, e o modelo previu corretamente este evento.

A partir das frequências obtidas na matriz de confusão de VP, FN, FP e VN, são geradas as métricas de Acurácia (3.2), Precisão (3.3), Sensibilidade (3.4) e F1-Score (3.5) como métricas de avaliação do modelo.

$$
\begin{gathered}
\text { Acuracia }=\frac{V P+V N}{V P+F P+V N+F N} \\
\text { Precisao }=\frac{V P}{V P+F P}
\end{gathered}
$$




$$
\begin{gathered}
\text { Sensibilidade }=\frac{V P}{V P+F N} \\
F 1 \_ \text {Score }=2 * \frac{(\text { Precisao } \times \text { Sensibilidade })}{\text { Precisao }+ \text { Sensibilidade }}
\end{gathered}
$$

Além das métricas derivadas de matriz de confusão o trabalho utilizará a estatística Kolmogorov-Smirnov (KS). Esta métrica é muito importante para verificar se o modelo é capaz de distinguir entre eventos e não eventos e assim mensurar o poder discriminatório de um modelo. Para calcular a métrica, o primeiro passo é dividir a distribuição de probabilidade em percentis e, em seguida, calcular o percentual cumulativo de eventos e não eventos em cada percentil e então verificar onde a diferença é máxima. A estatística KS é definida pela Equação 3.6, sendo $F_{1, n} \mathrm{e}$ $F_{2, m}$ são as funções de distribuição empíricas de eventos e não eventos respectivamente, e sup é a função que obtém a máxima diferença de um percentil $x$.

$$
K S_{n, m}=\sup _{x}\left|F_{1, n}(x)-F_{2, m}(x)\right|
$$

\subsubsection{Utilização do conhecimento}

Este trabalho tem caráter experimental, porém, tem como objetivo avaliar metodologias que podem ser empregadas em sistemas de apoio a tomada de decisão na área operacional das empresas e podem auxiliar as mesmas no atendimento de seus clientes elevando o nível de satisfação dos consumidores, gerando como benefício a satisfação de clientes e redução de risco de imagem das empresas. Na Seção 3.2, será apresentado uma proposta de utilização do modelo em produção para triagem de reclamações com baixa probabilidade de resolutividade e direcionamento para um fluxo especial de atendimento.

\subsection{Proposta de atendimento com triagem de reclama- ções}

Na Seção anterior foi apresentado a metodologia que este trabalho seguiu para a construção de modelos aplicados na classificação de resolutividade de reclamações. Como contribuição para a etapa de utilização do conhecimento, este trabalho traz algumas propostas de aplicação do modelo desenvolvido em um processo de atendimento na indústria. O trabalho foi desenvolvido utilizando dados de reclamações da plataforma de ODR ReclameAQUI, porém, a proposta aqui definida pode ir além e ser aplicada dentro de qualquer processo de atendimento das reclamações, como as reclamações enviadas diretamente ao SAC.

Em um processo de atendimento de reclamação tradicional, o reclamante envia sua reclamação por meio da plataforma de ODR e o SAC nível básico coordena o atendimento e 
formaliza a solução na plataforma. A resolução dada pelo atendimento pode ou não atender a necessidade do cliente, e o mesmo irá formalizar na plataforma ao finalizar a reclamação. Neste cenário, é proposto neste trabalho a utilização de modelos de triagem para direcionamento de um conjunto de reclamações com baixa probabilidade de resolução ao nível de atendimento especial (Figura 13). Um nível de atendimento especial pode envolver mais acessos a informação e tomada de decisão, um canal especial de resposta com custo maior e/ou concessão de benefícios ao cliente.

Os modelos de triagem no processo de atendimento (Figura 13), tem como objetivo classificar a resolutividade das reclamações de forma preemptiva, direcionando dentro da política de atendimento os casos com menor probabilidade de resolutividade para o atendimento especial. O modelo de triagem 1 será treinado com dados textuais das narrativas dos clientes, enquanto que o modelo de triagem 2 será treinado também com as narrativas da empresa.

Figura 13 - Processo de atendimento proposto. Gerado pelo autor.

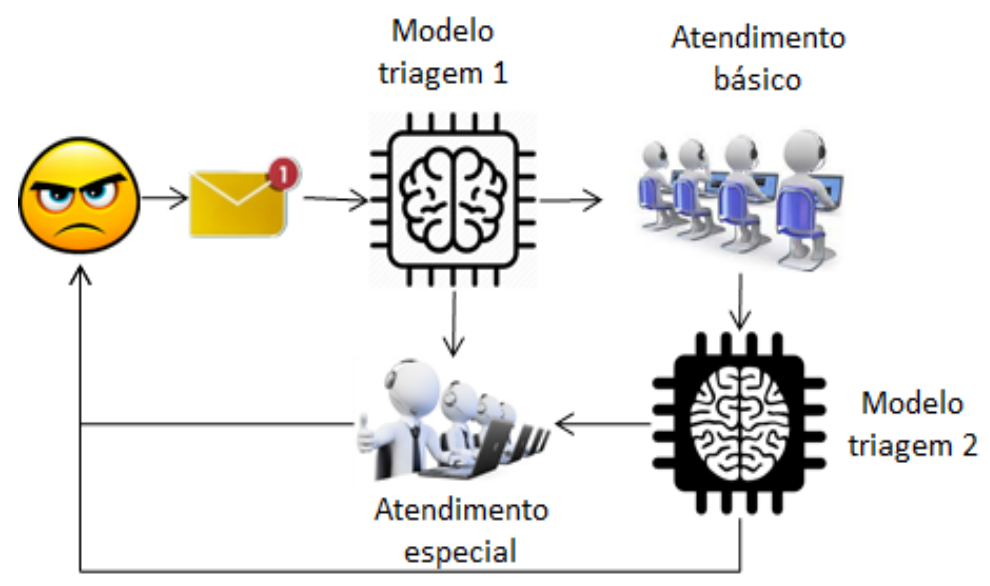

Um nível de atendimento especial envolve um custo maior de operação, pois pode necessitar de profissionais mais qualificados, canais de atendimento exclusivos, maior autonomia para tomada de decisão e capacidade de concessão de brindes e/ou benefícios aos clientes. Um dos grandes desafios da operacionalização de um fluxo de atendimento especial é conciliar a capacidade de atendimento com uma alta demanda eventual. Nesse cenário, é necessário uma estratégia de atendimento que envolva priorização das reclamações:

- Priorização por capacidade de atendimento: esta é a estratégia mais simples de operacionalização, onde é definido uma capacidade máxima de atendimento X. A partir da capacidade definida, é priorizada pela probabilidade dada pelo modelo as X reclamações com menor probabilidade de resolução e direcionadas ao atendimento especial.

- Priorização por valor do cliente: esta estratégia pode priorizar por segmentos de renda, rentabilidade do cliente, valor potencial que o cliente pode originar e também pela classe de pessoas expostas publicamente que geralmente são grandes influenciadores. 
- Priorização por estratégia de produto: esta estratégia pode seguir por qual produto o cliente está reclamando ou se o cliente que está reclamando possui relacionamento por um produto de interesse. A priorização pode ocorrer por produtos que geram maior rentabilidade ou por produtos que tem grande valor estratégico e a empresa quer minimizar risco de imagem sobre ele.

- Priorização híbrida: nesta estratégia ocorre combinação das estratégias anteriores, por exemplo, prioriza-se primeiro os melhores segmentos de clientes e se sobrar capacidade de atendimento pode haver priorização por produtos com rentabilidades mais altas.

Nesta seção foi apresentado um conjunto de propostas para utilização do conhecimento gerado no processo de atendimento de reclamações. A escolha de um bom modelo de predição depende da estratégia da operação de atendimento, sendo que a capacidade de ordenação de risco do modelo torna-se preponderante nessa escolha.

\subsection{Considerações finais}

Neste capítulo foi apresentado uma metodologia de aplicação de modelos utilizando técnicas de MT com objetivo de triar reclamações com baixa probabilidade de resolutividade. Foi proposto também um processo de atendimento que utiliza esses modelos com intuito de minimizar a probabilidade de não-resolução da reclamação.

Utilizando como base a metodologia proposta neste capítulo, no próximo capítulo será apresentado os detalhes da avaliação experimental dos modelos testados em 2 cenários de implementação dentro do processo de atendimento de reclamações com objetivo de minimizar o risco de insatisfação de clientes. 



\section{AVALIAÇÃO EXPERIMENTAL}

Neste capítulo o processo descrito no Capítulo 3 para classificação de resolutividade das reclamações é avaliado experimentalmente. São apresentados os resultados da avaliação experimental conforme descrito na Figura 14, que apresenta o processo de avaliação dos classificadores em 2 pontos do fluxo de atendimento. Na avaliação 1, o modelo apoia a triagem correta da reclamação para o nível de atendimento adequado considerando somente a narrativa de reclamação cliente. Este cenário de avaliação é referenciado como Modelagem com Dados Textuais de Reclamações (MOD1). Na avaliação 2, o modelo considera a narrativa de reclamação e a narrativa da resposta, permitindo assim a adequação da resolução por outro nível de atendimento de acordo com ambas narrativas. Este cenário de avaliação é referenciado como Modelagem com Dados Textuais de Reclamações e Respostas (MOD2).

Figura 14 - Fluxo das reclamações e avaliação dos classificadores. Gerado pelo autor.

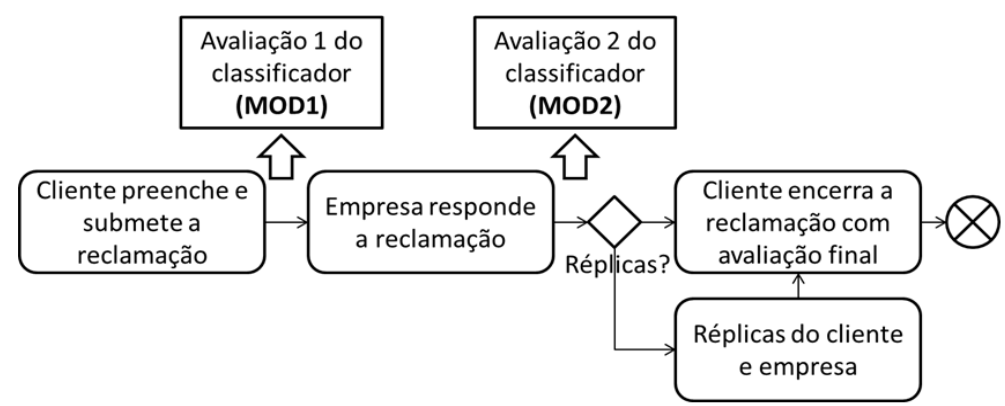

Os resultados da Análise Exploratória de Dados (AED) utilizando técnicas de exploração de textos serão apresentados na seção 4.1, com objetivo de entender melhor o comportamento dos dados utilizados antes de iniciar a modelagem. As sessões 4.2 e 4.3 apresentarão sob a mesma estrutura os resultados de avaliação experimental dos cenários MOD1 e MOD2. Nestas avaliações serão apresentados os resultados dos modelos com base nas métricas de acurácia, precisão, revocação, f1-score e KS-score. Na seção 4.4, os resultados dos cenários MOD1 e MOD2 serão comparados com foco na viabilidade de implementação. 


\subsection{Análise exploratória de dados}

Os dados utilizados na avaliação experimental contemplam 6.096 reclamações finalizadas de um dos principais bancos brasileiros. As reclamações foram originadas na plataforma ReclameAQUI entre abril de 2020 e janeiro de 2021. A resolutividade é a variável alvo utilizada no problema de classificação deste trabalho e a mesma possui comportamento balanceado entre as classes. Na Figura 15 é apresentado a distribuição entre as classes Resolvido (3.335) e Nãoresolvido (2.761) ou percentualmente $54.7 \%$ e $45.3 \%$ respectivamente, ou seja, é uma variável binária sem comportamento de classe rara.

Figura 15 - Distribuição da variável de resolutividade. Gerado pelo autor.

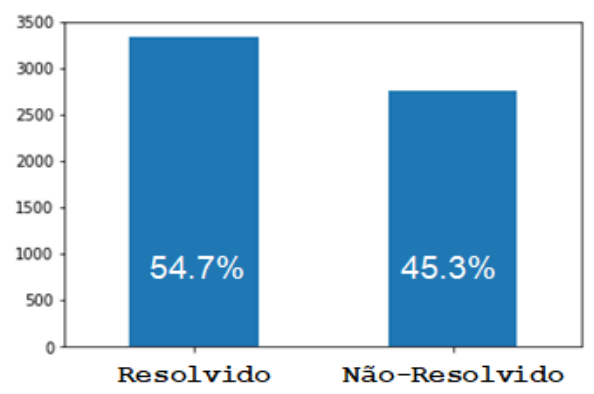

Como passo inicial em uma exploração de dados textuais, esta exploração buscou visualizar a quantidade de palavras dos documentos e também quais são as palavras que mais ocorrem nesses documentos. Na Figura 16 são mostrados os histogramas de quantidade de palavras (sem stopwords) das narrativas de reclamações e também das narrativas das respostas da empresa. Neste gráfico, é possível ver que no geral as reclamações possuem menos palavras que as respostas, sendo que as medianas são 89 e 116 palavras respectivamente. Um comprimento maior na resposta pode ser justificado por alguns fatores como tentativa de mostrar atenção na resolução do problema e também pela ocorrência de frases de efeito que a empresa utiliza em todas as respostas, como: "Olá, nós do banco XX sempre estamos atentos às suas necessidades...".

Figura 16 - Histograma de quantidade de palavras nas reclamações e respostas. Gerado pelo autor.

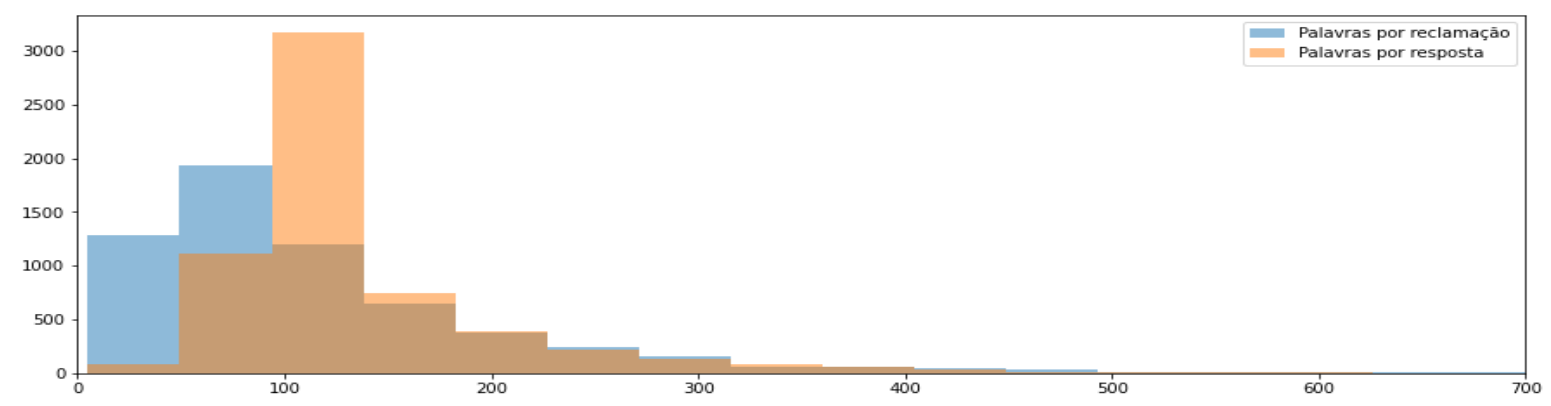

Na Figura 17 são apresentadas as frequências (sem stopwords) das 50 palavras com maior ocorrência nas narrativas de reclamações e também das narrativas das respostas da empresa. A distribuição de frequência das respostas mostra que as 50 palavras mais comuns 
possuem frequência mais elevada quando comparado as reclamações, mostrando assim uma maior padronização e uma menor diversidade textual.

Figura 17 - Frequência das 50 palavras mais comuns nas reclamações e respostas. Gerado pelo autor.
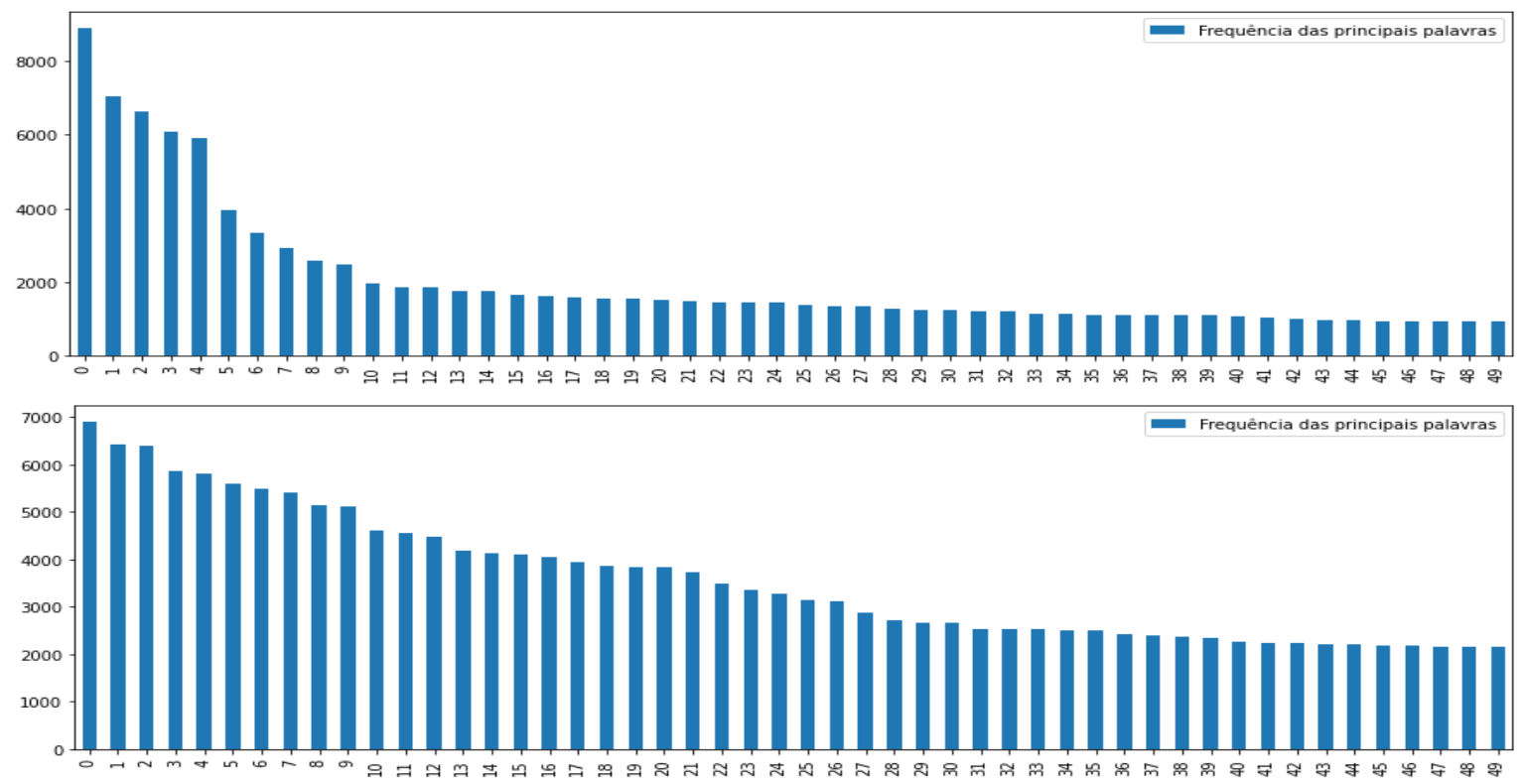

Na nuvem de palavras da Figura 18 são mostrados as 500 palavras mais relevantes das reclamações e respostas respectivamente. Neste gráfico também é possível constatar que há grande concentração de algumas palavras ou expressões nas respostas, enquanto que as reclamações possuem uma maior diversidade textual.

Figura 18 - Nuvem de palavras das reclamações e das respostas respectivamente. Gerado pelo autor.

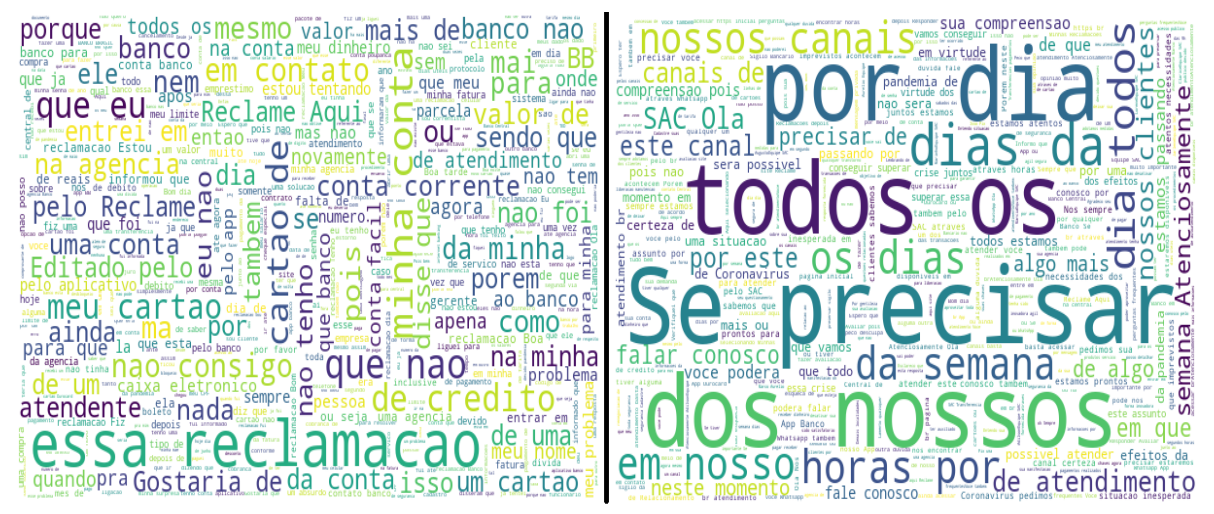

Em ambos os cenários de modelagem (MOD1 e MOD2) os dados foram separados utilizando holdout 90/10, sendo que $90 \%$ dos dados (5487 reclamações) foram utilizadas para treino e $10 \%$ (610 reclamações) foram utilizados para teste. Na tabela 3 são mostrados as métricas do pré-processamento, sendo que é importante destacar a baixa diferença entre as métricas de treino e teste. Estas métricas são importante para garantir que o conjunto de teste não destoe do conjunto de treinamento. 
Tabela 3 - Métricas de treino e teste para MOD1 e MOD2

\begin{tabular}{|c|c|c|c|c|c|}
\multicolumn{2}{|c}{} & $\begin{array}{c}\text { Quantidade } \\
\text { de registros }\end{array}$ & $\begin{array}{l}\text { Média de } \\
\text { palavras }\end{array}$ & $\begin{array}{l}\text { Percentil 95 } \\
\text { palavras }\end{array}$ & $\begin{array}{l}\text { Percentil 99 } \\
\text { palavras }\end{array}$ \\
\hline MOD1 & Treino & 5487 & 118 & 304 & 496 \\
\cline { 3 - 6 } & Teste & 610 & 119 & 303 & 501 \\
\hline MOD2 & $\begin{array}{c}\text { Treino } \\
\text { Teste }\end{array}$ & 5487 & 254 & 513 & 529 \\
\cline { 3 - 6 } & & 610 & 254 & 506 & 531 \\
\hline
\end{tabular}

\subsection{Avaliação experimental do cenário MOD1}

Os resultados apresentados nesta seção foram obtidos do conjunto de dados de teste. Para uma melhor avaliação do desempenho de discriminação das classes, a saída considerada do modelo foi a probabilidade, ou seja, quanto mais próximo de 0 maior a probabilidade do modelo entender que aquela reclamação foi resolvida e o inverso quando a saída está próxima de 1.

Em problemas de classificação é normal definir o limiar em 0.5 para determinar a classe, porém, esta não é necessariamente a forma otimizada de determinar o limiar. Existem algumas formas de determinar o melhor limiar de discriminação das classes e neste trabalho foi adotada a curva ROC. A curva ROC nos ajuda a encontrar o limiar que maximiza a relação em que taxa de verdadeiros-positivos (True Positive Rate) é alta e taxa de falsos-positivos (False Positive Rate) é baixa. Em muitos cenários de classificação, o custo de falsos positivos e falsos negativos não é o mesmo, porém neste trabalho eles foram tratados como equivalentes. Dado o contexto, a curva ROC pode ser usada para determinar o limiar de probabilidade ideal para um modelo de classificação. Na Figura 19 são apresentados os resultados da curva ROC para cada um dos modelos, sendo que os melhores limiares encontrados foram $0.41,0.41$ e 0.43 para os modelos NBSVM, FastText e DistilBERT respectivamente.

Figura 19 - MOD1: Curva ROC e melhor limiar (NBSVM, FastText e DistilBERT). Gerado pelo autor.
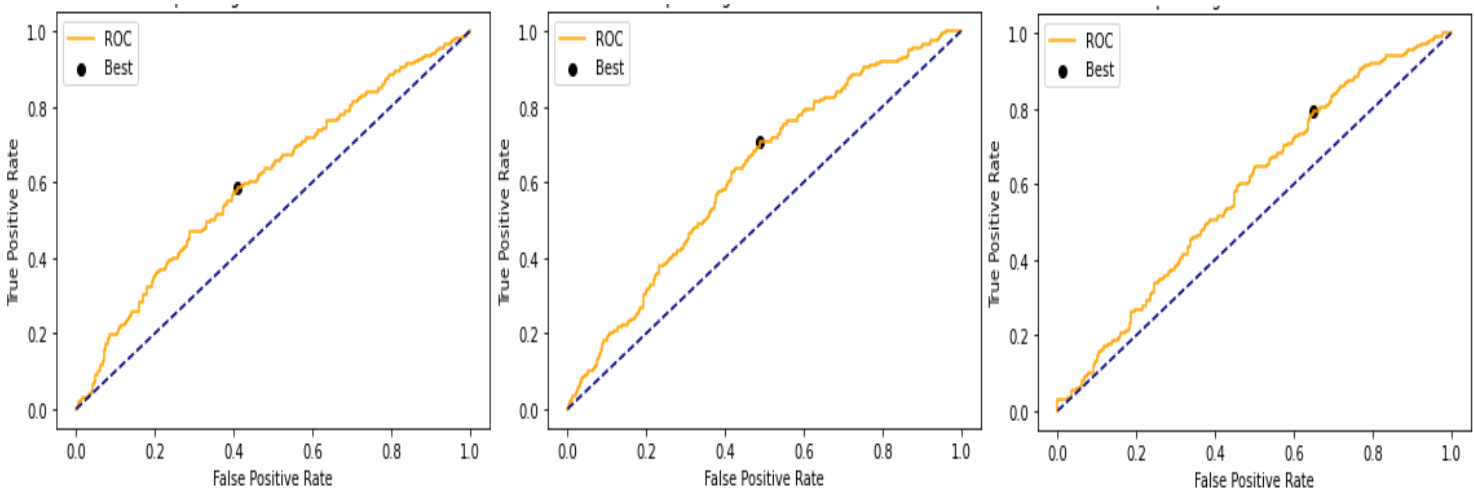

Os resultados mostrados na Tabela 4 derivados da matriz de confusão foram obtidos com limiar dado pela curva ROC, conforme descrito anteriormente. Além disso, as métricas de Precisão, Revocação e F1-Score possuem aberturas por classes, enquanto que para as métricas de Acurácia, KS e AUC são apresentados os resultados de ambas as classes. Dado os resultados é possível notar que o FastText obteve o melhor desempenho na maior parte das métricas analisadas 
incluindo o KS. Esse resultado superior pode ser justificado dado a capacidade do FastText de gerar embeddings sobre textos escritos sem muita criticidade, escritos de maneira informal e com uso de abreviações, como é o caso das narrativas das reclamações. O FastText leva em consideração a estrutura interna das palavras enquanto aprende as representações das palavras, o que pode ser muito útil para idiomas morfologicamente ricos e também para palavras que ocorrem raramente.

Tabela 4 - Resultados dos modelos em MOD1

\begin{tabular}{|l|l|l|l|l|l|l|l|}
\hline Modelo & Classes & Precisão & Revocação & F1-Score & Acur & KS & AUC \\
\hline \multirow{2}{*}{ NBSVM } & Resolvido & 0.63 & 0.59 & 0.61 & 0.59 & 0.177 & 0.604 \\
\cline { 3 - 5 } & Não-resolvido & 0.55 & 0.59 & 0.57 & & & \\
\hline \multirow{2}{*}{ FastText } & Resolvido & 0.67 & 0.51 & 0.58 & 0.60 & 0.215 & 0.624 \\
& Não-resolvidido & 0.55 & 0.71 & 0.62 & & & \\
\cline { 3 - 5 } & Resolvido & 0.66 & 0.35 & 0.46 & 0.56 & 0.139 & 0.585 \\
\cline { 3 - 5 } & Não-resolvido & 0.51 & 0.79 & 0.62 & & & \\
\hline
\end{tabular}

É importante ressaltar que a métrica KS é derivada do teste de Kolmogorov-Smirnov, sendo esta muito utilizada na indústria financeira para avaliação de performance de modelos. No KS é avaliado qual é o poder de separação das classes binárias ordenado pela probabilidade dada pelo modelo. $\mathrm{O}$ valor de KS usado é o ponto onde as classes obtiveram a maior distancia de separação percentual. Na Figura 20 são apresentados as curvas das estatísticas KS de cada um dos modelos, sendo possível visualizar uma abertura superior das curvas do FastText em relação aos demais modelos, o que representa uma melhor capacidade de ordenação das classes por meio da probabilidade do modelo.

Figura 20 - MOD1: Estatística KS (NBSVM, FastText e DistilBERT). Gerado pelo autor.
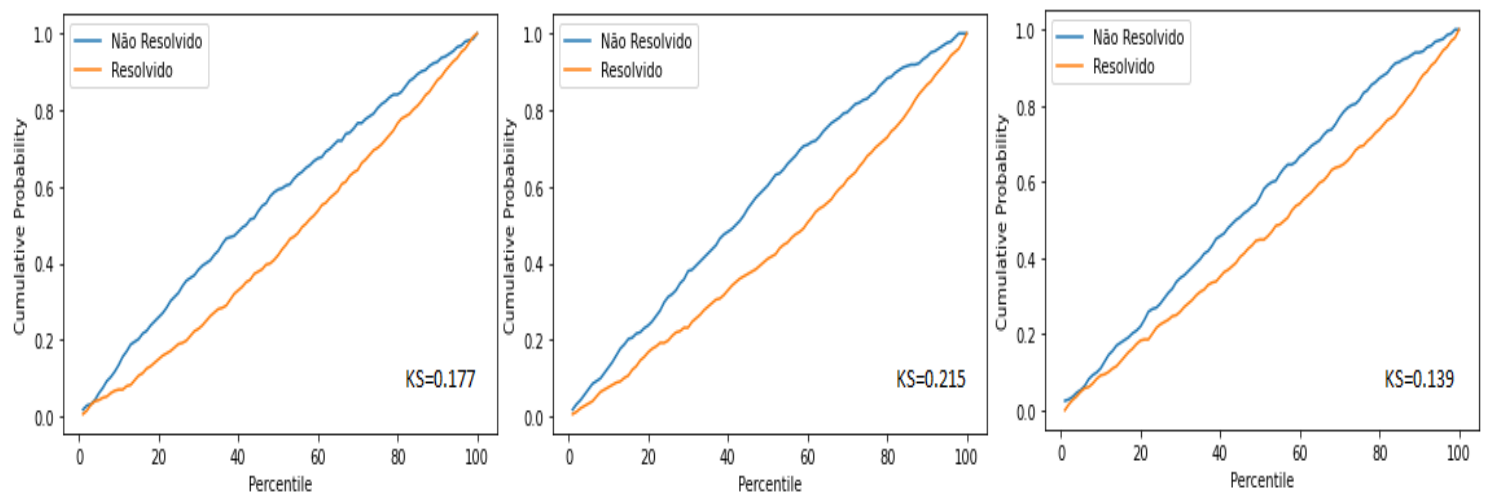

Dentre as estratégias de priorização apresentadas na seção 3.2, a priorização por capacidade de atendimento é a mais simples de operacionalizar. Nessa estratégia deve ser definido um quantitativo de reclamações que podem ser encaminhadas para tratamento especial e priorizadas pela probabilidade de Não-resolução. Por este motivo é importante uma avaliação das acurácias por decis, sendo que a acurácia dos maiores decis ganham grande destaque nessa avaliação. Nos gráficos da Figura 21 são apresentados os resultados de acurácia por decil, e nele podemos notar 
que o NBSVM possui resultado ligeiramente superior quando consideramos, por exemplo, os decis 9 e 10 juntos. Entretanto um resultado mais aplicável no processo de atendimento seria um resultado em $\mathrm{U}$, sendo esperado uma acurácia superior nas pontas com uma maior aplicabilidade na triagem.

Figura 21 - MOD1: Acurácia por decil de score (NBSVM, FastText e DistilBERT). Gerado pelo autor.
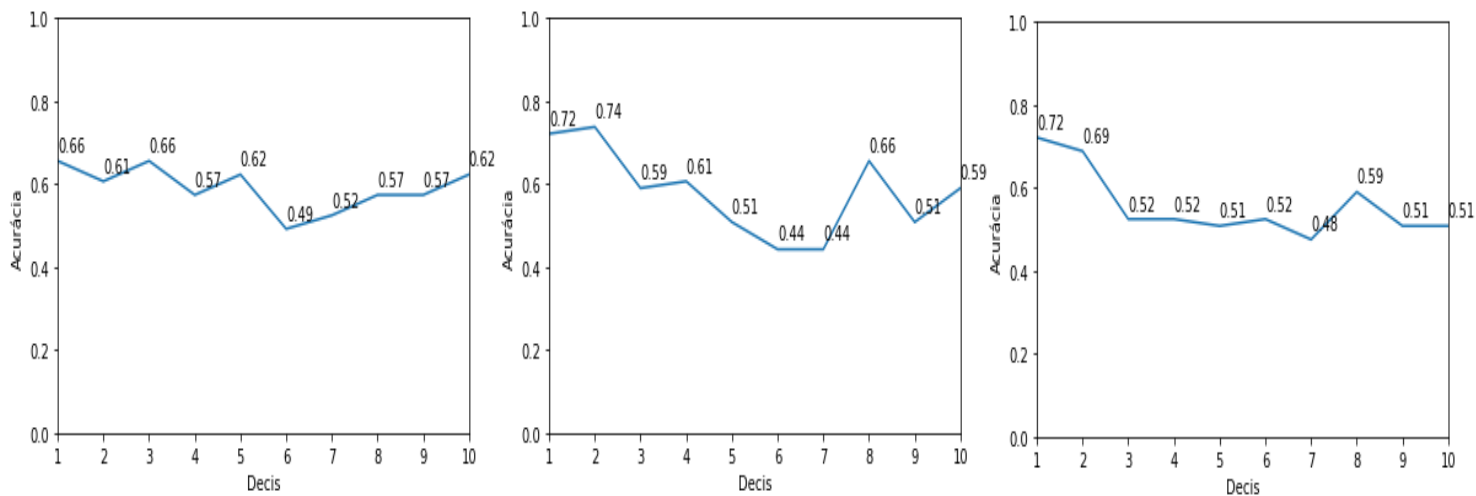

Foram apresentados nesta seção os resultados de discriminação da resolutividade da reclamação considerando apenas a narrativa da reclamação Dentre os resultados apresentados, o FastText apresentou um desempenho ligeiramente superior aos outros modelos empregados.

Algumas nuances da reclamação podem indicar uma maior probabilidade de nãoresolutividade, por exemplo, termos que indiquem produtos ou serviços que a empresa possua dificuldade de atender as expectativas de seus clientes. Nesse caso a estatística de ocorrência de termos específicos em relação a classe alvo pode discriminar melhor que a semântica do texto e isso pode justificar porque um modelo estatístico como o NBSVM é superior ao modelo de linguagem DistilBERT.

Este é um problema onde a capacidade humana também teria dificuldade de antever a resolução, pois dado a semântica do texto da reclamação, é complexo classificar se a reclamação será resolvida ou não. Essa interpretação gera uma hipótese que no momento da submissão da reclamação o cliente não está propenso a finalizar a reclamação como resolvida ou não, e isso irá depender da solução apresentada pela empresa. Neste cenário, a utilização da narrativa da resposta da empresa em conjunto com a reclamação considerada no cenário MOD2 se faz necessário.

\subsection{Avaliação experimental do cenário MOD2}

Esta seção apresenta os resultados da avaliação experimental considerando os dados textuais das reclamações e das respostas da empresa. Dado que o conjunto de dados foi alterado uma nova análise da curva ROC foi efetuada para encontrar o limiar mais adequado considerando a melhor relação verdadeiros-positivos e falsos-positivos. Na Figura 22 são apresentados os 
resultados da curva ROC para cada um dos modelos, sendo que os melhores limiares encontrados foram $0.37,0.57$ e 0.61 para os modelos NBSVM, FastText e DistilBERT respectivamente.

Figura 22 - MOD2: Curva ROC e melhor limiar (NBSVM, FastText e DistilBERT). Gerado pelo autor.
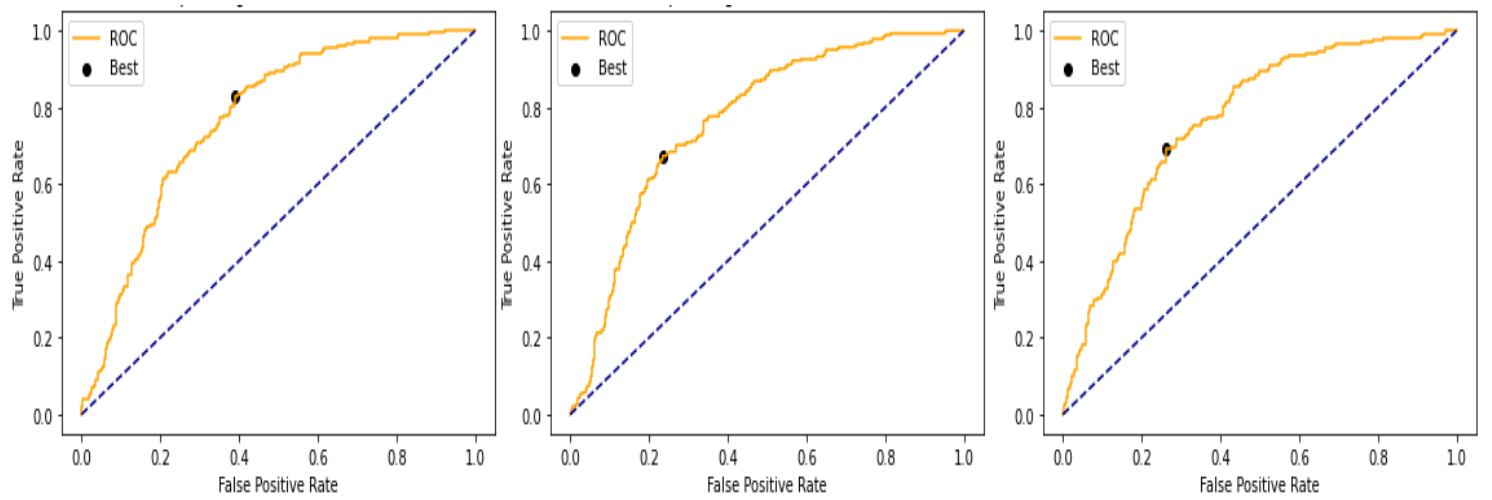

Na Tabela 5 são mostrados os resultados dos modelos em MOD2 e é possível destacar que os mesmos apresentaram resultados equivalentes tanto em métricas de matriz de confusão quanto em KS e AUC. Interessante notar que para as métricas de Acurácia, KS e AUC, os classificadores obtiveram uma diferença máxima de $1 \%$, o que pode ser considerado um resultado muito próximo. É importante destacar que resultados de MOD2 são substancialmente mais relevantes que os resultados de MOD1, chegando a ter 25, 22 e 29 pontos percentuais de incremento de KS nos modelos NBSVM, FastText e DistilBERT respectivamente.

Tabela 5 - Resultados dos modelos em MOD2

\begin{tabular}{|l|l|l|l|l|l|l|l|}
\hline Modelo & Classes & Precisão & Revocação & F1-Score & Acur & KS & AUC \\
\hline NBSVM & Resolvido & 0.81 & 0.61 & 0.69 & 0.71 & 0.434 & 0.769 \\
\cline { 3 - 5 } & Não-resolvido & 0.65 & 0.83 & 0.73 & & & \\
\hline \multirow{2}{*}{ FastText } & Resolvido & 0.73 & 0.77 & 0.75 & 0.72 & 0.436 & 0.767 \\
& Não-resolvidido & 0.71 & 0.67 & 0.69 & & & \\
\cline { 3 - 5 } & Resolvido & 0.74 & 0.74 & 0.74 & 0.72 & 0.429 & 0.767 \\
\cline { 3 - 5 } & Não-resolvido & 0.69 & 0.69 & 0.69 & & & \\
\hline
\end{tabular}

Na Figura 23 são mostrados os resultados de estatística KS obtidos para os modelos NBSVM, FastText e DistilBERT respectivamente. As distribuições de probabilidade cumulativa dos 3 modelos apresentaram pouca diferença de separabilidade entre elas, reforçando que os resultados podem ser considerados equivalentes. Na análise de acurácia por decil da Figura 24, o DistilBERT apresentou o comportamento mais próximo do esperado em U, ou seja, dentre os modelos testados, ele apresenta uma acurácia superior nas probabilidades extremas o que pode torná-lo o modelo escolhido em uma estratégia de atendimento com capacidade reduzida de atendimento especial. 
Figura 23 - MOD2: Estatística KS (NBSVM, FastText e DistilBERT). Gerado pelo autor.
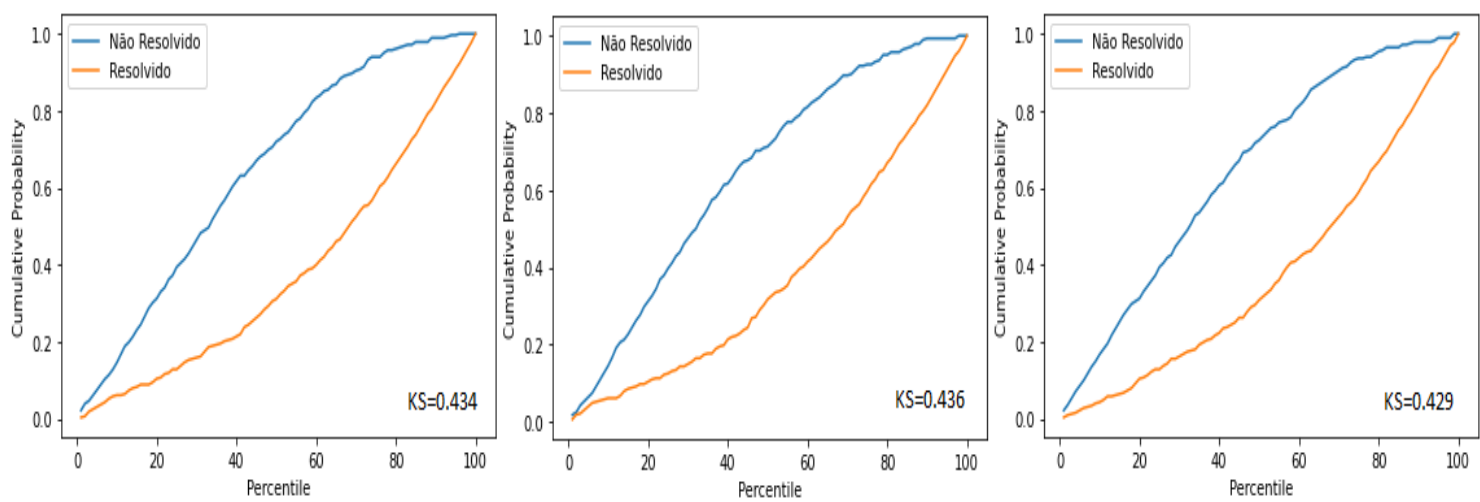

Figura 24 - MOD2: Acurácia por decil de score (NBSVM, FastText e DistilBERT). Gerado pelo autor.
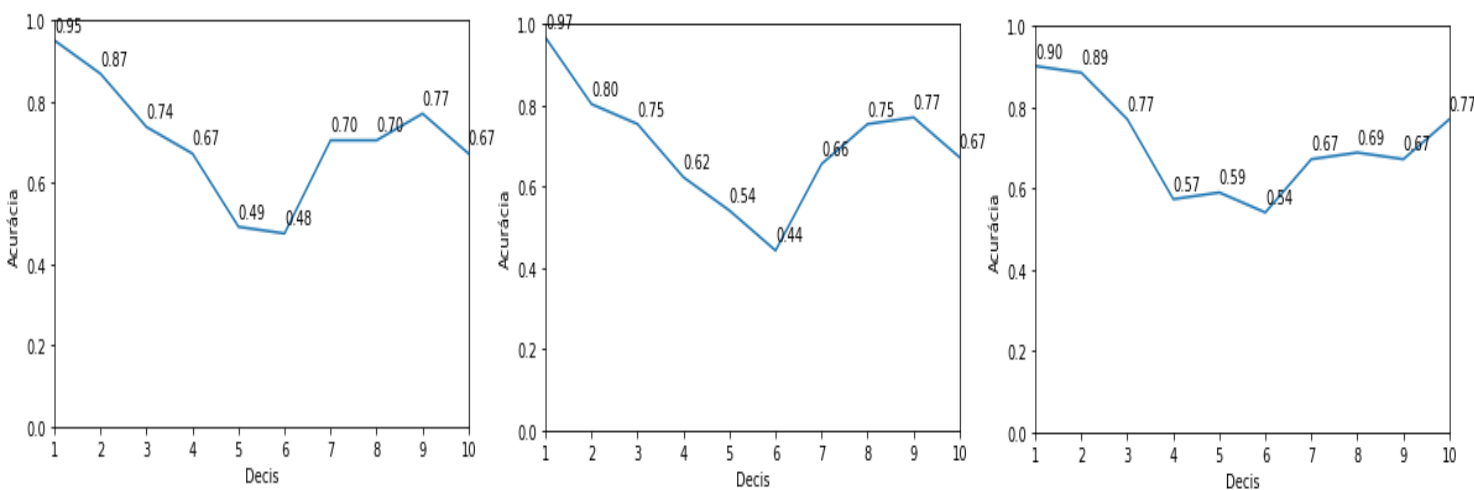

\subsection{Considerações finais}

Os resultados apresentados neste capítulo mostraram que no cenário MOD2 todos os modelos apresentaram resultados equivalentes. Entretanto é importante destacar que resultados de MOD2 são substancialmente mais relevantes que os resultados de MOD1, mostrando que é possível classificar a resolutividade da reclamação de forma preemptiva combinando a narrativa de reclamação do cliente e a narrativa de resposta da empresa. A escolha do melhor modelo de predição depende da estratégia de atuação da operação de atendimento e a adoção dos modelos treinados em MOD1 não é conclusiva e depende bastante da capacidade de atendimento especial e do apetite de risco da empresa.

Para implantação de um modelo em produção o requisito não-funcional importante a ser considerado é o tempo de processamento do modelo escolhido. Esse requisito pode variar bastante de acordo com a arquitetura computacional empregada, porém nos testes realizados o DistilBERT levou em média 100 vezes mais tempo para execução que os demais, e dependendo da arquitetura de sistemas empregado na solução da empresa esse custo elevado de processamento pode inviabilizar a implantação.

É importante destacar que os classificadores não foram testados sobre os dados das réplicas, pois grande parte dos dados obtidos não-possuem réplicas e o classificador treinado no cenário MOD2 também poderia ser aplicado sobre as réplicas. 
O emponderamento dado ao consumidor para exigir seus direitos por meio das mídias digitais em contraste com a necessidade das empresas na evolução continua de indicadores de satisfação dos clientes e otimização de custos, geram um cenário desafiador nas áreas responsáveis pelo atendimento de reclamações dos clientes. Empresas que optam por ignorar as reclamações nos meios digitais tem que conviver com deterioração de imagem e perda de mercado. Em contrapartida, as empresas que não aplicam inteligência no atendimento de clientes acabam deixando parte do lucro em processos ineficientes.

Neste trabalho foi proposto a utilização de técnicas de MT em um fluxo de triagem de reclamações com objetivo de minimizar a probabilidade de não-resolução das reclamações. Os modelos de representação e classificação de textos avaliados foram escolhidos com base em 3 arquiteturas distintas de complexidade, sendo elas: NBSVM, FastText e DistilBERT. Considerando que a capacidade humana também teria dificuldade de antever a resolução com apenas o texto da reclamação, o problema foi dividido em 2 cenários de avaliação experimental nomeados de MOD1 e MOD2, sendo que MOD2 possui os dados da resposta da empresa como diferencial.

Os resultados apresentados para MOD1 mostraram uma baixa capacidade de discriminação da resolutividade da reclamação considerando apenas a narrativa da reclamação, com desempenho ligeiramente superior do FastText. Nesse caso, a estatística de ocorrência de termos específicos em relação à resolução pode discriminar melhor que a semântica do texto e isso pode justificar porque os modelos mais simples podem atingir melhores resultados.

Os resultados apresentados em MOD2 foram substancialmente mais relevantes que os resultados de MOD1, chegando a aumentar 25, 22 e 29 pontos percentuais de KS nos modelos NBSVM, FastText e DistilBERT respectivamente. Estes resultados mostraram que é possível classificar a resolutividade da reclamação de forma preemptiva combinando a narrativa de reclamação do cliente e a narrativa de resposta da empresa, e com isso aplicar em uma estratégia 
de atendimento diferenciado para casos com alta probabilidade de não-resolução.

Os resultados mostraram também que a capacidade de compreensão semântica do DistilBERT não agregou melhores resultados ao problema. Os modelos NBSVM e FastText depois de treinados executaram em média 100 vezes mais rápido que o DistilBERT e isso é um fator importante na escolha do modelo. A escolha de um bom modelo de predição depende da estratégia de atuação da operação de atendimento, sendo que a capacidade de ordenação do risco torna-se preponderante nessa escolha.

Neste projeto foram aplicados modelos de classificação na resolutividade de reclamações, pois assumiu-se a premissa que resolutividade é a variável que mais impacta na satisfação dos clientes. Dependendo da estratégia de atendimento empregada pela empresa, outras variáveis disponíveis na plataforma podem ser mais interessantes, como "voltaria a fazer negócio?" e "nota do atendimento".

Para as variáveis descritivas, o foco do trabalho foi na utilização dos dados dos textos das narrativas de reclamação e resposta da empresa. Porém, outras variáveis construídas com base nos dados da plataforma ReclameAQUI também podem ser empregadas:

- Tempo decorrido desde a submissão da reclamação;

- Localidade do cliente;

- Re-interações das reclamações;

- Resolutividade das reclamações em outras empresas;

- Narrativa de eventuais réplicas;

As bases de dados internas das empresas também podem ser usadas nesta aplicação, dado que a empresa recebe os dados pessoais do cliente reclamante e pode enriquecer com dados internos. Considerando que a empresa faz parte do sistema financeiro brasileiro, a mesma pode utilizar variáveis de perfil econômico do cliente, inadimplência interna e externa, reclamações anteriores, dados cadastrais, entre outros. A proposta de enriquecimento com outras variáveis teria como único objetivo modelar o contexto da reclamação e do cliente com o intuito de oferecer a melhor experiência na resolução do problema. 
AGGARWAL, C. C. Machine learning for text. [S.1.]: Springer, 2018. Citado nas páginas 31, $32,33,34,35,36,41$ e 45.

Neural networks and deep learning. [S.1.]: Springer, 2018. Citado nas páginas 40 e 41.

ALEXA. @ Alexa an amazon.com company. [S.1.], 2021. Disponível em: <https://www.alexa. com/topsites/countries/BR>. Acesso em: 09/09/2021. Citado na página 24.

ARBIX, D. d. A. Resoluções online de controvérsias: tecnologias e jurisdições. Tese (Doutorado) - Universidade de São Paulo, 2015. Citado na página 28.

BCB2021. Banco Central do Brasil. [S.1.], 2021. Disponível em: <https://www.bcb.gov.br/ estabilidadefinanceira/sfn>. Acesso em: 09/09/2021. Citado na página 28.

Banco Central do Brasil. [S.1.], 2021. Disponível em: <https://www.bcb.gov.br/ acessoinformacao/registrar_reclamacao>. Acesso em: 09/09/2021. Citado na página 28.

BOJANOWSKI, P.; GRAVE, E.; JOULIN, A.; MIKOLOV, T. Enriching word vectors with subword information. arXiv preprint arXiv:1607.04606, 2016. Citado nas páginas 36 e 51.

BRASIL. Decreto $n^{0}$ 6.523, de 31 de julho de 2008. regulamenta a lei no 8.078, de 11 de setembro de 1990, para fixar normas gerais sobre o serviço de atendimento ao consumidor sac. Diário Oficial [da] República Federativa do Brasil, Brasília, DF, 2008. Disponível em: $<$ http://www.planalto.gov.br/ccivil_03/_ato2007-2010/2008/decreto/d6523.htm>. Acesso em: 09/09/2021. Citado nas páginas 23 e 27.

CAROSIA, A.; COELHO, G. P.; SILVA, A. Analyzing the brazilian financial market through portuguese sentiment analysis in social media. Applied Artificial Intelligence, Taylor \& Francis, v. 34, n. 1, p. 1-19, 2020. Citado na página 25.

CHOLLET, F. et al. Keras. 2015. Disponível em: <https://keras.io> . Acesso em: 09/09/2021. Citado na página 50.

DAUPHIN, Y. N.; FAN, A.; AULI, M.; GRANGIER, D. Language modeling with gated convolutional networks. In: International conference on machine learning. [S.1.: s.n.], 2017. p. 933-941. Citado na página 34.

DEVLIN, J.; CHANG, M.-W.; LEE, K.; TOUTANOVA, K. Bert: Pre-training of deep bidirectional transformers for language understanding. arXiv preprint arXiv:1810.04805, 2018. Citado nas páginas $15,35,37,38,39$ e 51 .

EKINCI, Y.; CALDERON, J.; SIALA, H. Do personality traits predict' complaining' consumers? International Journal of Business Environment, Inderscience Publishers (IEL), v. 8, n. 1, p. 32-42, 2016. Citado na página 23. 
GALITSKY, B. A.; GONZÁLEZ, M. P.; CHESÑEVAR, C. I. A novel approach for classifying customer complaints through graphs similarities in argumentative dialogues. Decision Support Systems, Elsevier, v. 46, n. 3, p. 717-729, 2009. Citado na página 25.

GALLO, A. The value of keeping the right customers. Harvard business review, v. 29, p. 2014, 2014. Citado na página 30.

GONÇALVES, C. d. A. Análise de sentimentos em reclamações: uma aplicação no maior site de reclamações do Brasil. Tese (Doutorado), 2016. Citado na página 25.

GOOGLE. Colaboratory. [S.1.], 2021. Disponível em: <https://colab.research.google.com>. Acesso em: 09/09/2021. Citado na página 50.

GUERRA, S.; SALINAS, N. S. C. Resolução eletrônica de conflitos em agências reguladoras. Revista Direito GV, SciELO Brasil, v. 16, n. 1, 2020. Citado nas páginas 24 e 28.

HABIMANA, O.; LI, Y.; LI, R.; GU, X.; YU, G. Sentiment analysis using deep learning approaches: an overview. Science China Information Sciences, Springer, v. 63, n. 1, p. 1-36, 2020. Citado nas páginas 32 e 37.

HARRIS, Z. S. Distributional structure. WORD, Routledge, v. 10, n. 2-3, p. 146-162, 1954. Disponível em: <https://doi.org/10.1080/00437956.1954.11659520>. Citado na página 35.

HENNIG-THURAU, T.; GWINNER, K. P.; WALSH, G.; GREMLER, D. D. Electronic word-ofmouth via consumer-opinion platforms: what motivates consumers to articulate themselves on the internet? Journal of interactive marketing, Elsevier, v. 18, n. 1, p. 38-52, 2004. Citado na página 23.

HU, M.; LIU, B. Mining and summarizing customer reviews. In: Proceedings of the tenth ACM SIGKDD international conference on Knowledge discovery and data mining. [S.1.: s.n.], 2004. p. 168-177. Citado na página 25.

. Mining opinion features in customer reviews. In: AAAI. [S.1.: s.n.], 2004. v. 4, n. 4, p. 755-760. Citado na página 25.

IGLESIAS, B. L. S. A mineração de opinião em mídias sociais como ferramenta para medir a (in) satisfação do consumidor. 2020. Citado na página 42.

JOULIN, A.; GRAVE, E.; BOJANOWSKI, P.; MIKOLOV, T. Bag of tricks for efficient text classification. arXiv preprint arXiv:1607.01759, 2016. Citado na página 36.

Bag of tricks for efficient text classification. arXiv preprint arXiv:1607.01759, 2016. Citado na página 51.

JOUNG, J.; JUNG, K.; KO, S.; KIM, K. Customer complaints analysis using text mining and outcome-driven innovation method for market-oriented product development. Sustainability, Multidisciplinary Digital Publishing Institute, v. 11, n. 1, p. 40, 2019. Citado nas páginas 25, 31 e 42 .

KAUFMANN-KOHLER, G.; SCHULTZ, T. Online dispute resolution: challenges for contemporary justice. [S.1.]: Kluwer Law International BV, 2004. Citado na página 28.

KERAMATI, A.; GHANEEI, H.; MIRMOHAMMADI, S. M. Developing a prediction model for customer churn from electronic banking services using data mining. Financial Innovation, Springer, v. 2, n. 1, p. 10, 2016. Citado na página 31. 
KRISHNA, G. J.; RAVI, V.; REDDY, B. V.; ZAHEERUDDIN, M.; JAISWAL, H.; TEJA, P. S. R.; GAVVAL, R. Sentiment classification of indian banks' customer complaints. In: IEEE. TENCON 2019-2019 IEEE Region 10 Conference (TENCON). [S.1.], 2019. p. 429-434. Citado nas páginas 25 e 42.

LE, Q.; MIKOLOV, T. Distributed representations of sentences and documents. In: International conference on machine learning. [S.1.: s.n.], 2014. p. 1188-1196. Citado na página 36.

LI, B.; ZHAO, Z.; LIU, T.; WANG, P.; DU, X. Weighted neural bag-of-n-grams model: New baselines for text classification. In: Proceedings of COLING 2016, the 26th International Conference on Computational Linguistics: Technical Papers. [S.1.: s.n.], 2016. p. 1591-1600. Citado na página 40.

LIU, B. Sentiment analysis and opinion mining. Synthesis lectures on human language technologies, Morgan \& Claypool Publishers, v. 5, n. 1, p. 1-167, 2012. Citado na página 32 .

LIU, Y.; WAN, Y.; SU, X. Identifying individual expectations in service recovery through natural language processing and machine learning. Expert Systems with Applications, Elsevier, v. 131, p. 288-298, 2019. Citado nas páginas 30, 31 e 41.

MAIYA, A. S. ktrain: A low-code library for augmented machine learning. arXiv preprint arXiv:2004.10703, 2020. Citado na página 50.

MARCACINI, R. M. Aprendizado não supervisionado de hierarquias de tópicos a partir de coleções textuais dinâmicas. Tese (Doutorado) — Universidade de São Paulo, 2011. Citado na página 31.

MARCACINI, R. M.; ROSSI, R. G.; MATSUNO, I. P.; REZENDE, S. O. Cross-domain aspect extraction for sentiment analysis: A transductive learning approach. Decision Support Systems, Elsevier, v. 114, p. 70-80, 2018. Citado na página 37.

MARQUES, R. D. A resolução de disputas online (odr): do comércio eletrônico ao seu efeito transformados sobre o conceito e a prática do acesso à justiça (online dispute resolution (odr): From e-commerce to its transformative effect on the concept and practice of access to justice). Revista de Direito e as Novas Tecnologias, v. 5, 2019. Citado na página 24.

MIKOLOV, T.; CHEN, K.; CORRADO, G.; DEAN, J. Efficient estimation of word representations in vector space. arXiv preprint arXiv:1301.3781, 2013. Citado na página 36.

OLIVEIRA, L. V. C.; MOREIRA, R. V.; RIBEIRO, L. M. T. B.; CABRAL, H. L. T. B.; SOUZA, C. H. M. de. Procon virtual efetivando o direito do consumidor. 2016. Citado nas páginas 24 e 28.

PICIU, L.; DAMIAN, A.; TAPUS, N.; SIMION-CONSTANTINESCU, A.; DUMITRESCU, B. Deep recommender engine based on efficient product embeddings neural pipeline. In: IEEE. 2018 17th RoEduNet conference: networking in education and research (RoEduNet). [S.1.], 2018. p. 1-6. Citado na página 32.

RECLAMEAQUI. ReclameAQUI. [S.1.], 2021. Disponível em: <https://www.reclameaqui.com. br/institucional/> . Acesso em: 09/09/2021. Citado nas páginas 15, 24, 29, 30 e 47.

REICHHELD, F. F. The one number you need to grow. Harvard business review, v. 81, n. 12, p. 46-55, 2003. Citado nas páginas 25 e 30. 
REZENDE, S. O. Sistemas Inteligentes: Fundamentos e Aplicações. Barueri, SP: Editora Manole Ltda, 2003. ISBN 8520416837. Citado nas páginas 15, 31, 32, 39 e 45.

RIEKERT, M.; RIEKERT, M.; KLEIN, A. Simple baseline machine learning text classifiers for small datasets. SN Computer Science, Springer, v. 2, n. 3, p. 1-16, 2021. Citado na página 40.

ROSENBLATT, F. The perceptron: a probabilistic model for information storage and organization in the brain. Psychological review, American Psychological Association, v. 65, n. 6, p. 386, 1958. Citado na página 40.

ROSSI, R. G. Classificação automática de textos por meio de aprendizado de máquina baseado em redes. Tese (Doutorado) — Universidade de São Paulo, 2016. Citado nas páginas 32,33 e 34 .

SANH, V.; DEBUT, L.; CHAUMOND, J.; WOLF, T. DistilBERT, a distilled version of BERT: smaller, faster, cheaper and lighter. arXiv preprint arXiv:1910.01108, 2019. Citado nas páginas 38,49 e 51.

SCHMIDT-KESSEN, M. J.; NOGUEIRA, R.; GAMITO, M. C. Success or failure?-effectiveness of consumer odr platforms in brazil and in the eu. Journal of Consumer Policy, Springer, p. 1-28, 2020. Citado na página 24.

SENACON. Consumidor em Números 2019. [S.1.], 2020. Disponível em: <https://www. defesadoconsumidor.gov.br/images/2020/Consumidor-em-nmeros---2019.pdf>. Acesso em: 09/09/2021. Citado nas páginas 15, 28 e 29.

SEZGEN, E.; MASON, K. J.; MAYER, R. Voice of airline passenger: A text mining approach to understand customer satisfaction. Journal of Air Transport Management, Elsevier, v. 77, p. 65-74, 2019. Citado nas páginas 23, 30, 31, 32 e 41.

SILVA, A. V. Um modelo de classificação para o Reconhecimento de Entidades Nomeadas. Tese (Doutorado) — Universidade de São Paulo, 2020. Citado na página 37.

SINOARA, R. A.; CAMACHO-COLLADOS, J.; ROSSI, R. G.; NAVIGLI, R.; REZENDE, S. O. Knowledge-enhanced document embeddings for text classification. Knowledge-Based Systems, Elsevier, v. 163, p. 955-971, 2019. Citado nas páginas 33, 34 e 36.

SOUSA, G. N. d.; GUIMARÃES, I. d. S.; VIANA, J. A. N.; REINHOLD, O.; JUNIOR, A. F. L. J.; LOBATO, F. M. F. Análise do setor de telecomunicação brasileiro: Uma visão sobre reclamações. RISTI-Revista Ibérica de Sistemas e Tecnologias de Informação, Associação Ibérica de Sistemas e Tecnologias de Informação (AISTI), n. 37, p. 31-48, 2020. Citado nas páginas $23,24,25,31$ e 42 .

SUN, C.; QIU, X.; XU, Y.; HUANG, X. How to fine-tune bert for text classification? In: SPRINGER. China National Conference on Chinese Computational Linguistics. [S.1.], 2019. p. 194-206. Citado na página 49.

VASWANI, A.; SHAZEER, N.; PARMAR, N.; USZKOREIT, J.; JONES, L.; GOMEZ, A. N.; KAISER, Ł.; POLOSUKHIN, I. Attention is all you need. In: Advances in neural information processing systems. [S.1.: s.n.], 2017. p. 5998-6008. Citado na página 37. 
WANG, S. I.; MANNING, C. D. Baselines and bigrams: Simple, good sentiment and topic classification. In: Proceedings of the 50th Annual Meeting of the Association for Computational Linguistics (Volume 2: Short Papers). [S.1.: s.n.], 2012. p. 90-94. Citado nas páginas 39, 40 e 51.

WU, Y.; SCHUSTER, M.; CHEN, Z.; LE, Q. V.; NOROUZI, M.; MACHEREY, W.; KRIKUN, M.; CAO, Y.; GAO, Q.; MACHEREY, K. et al. Google's neural machine translation system: Bridging the gap between human and machine translation. arXiv preprint arXiv:1609.08144, 2016. Citado na página 37.

XAVIER, T. A. Avaliação da percepção do cliente no atendimento de urgência e emergência em um hospital na cidade de São Paulo. Tese (Doutorado), 2019. Citado na página 30.

YANG, W.; TAN, L.; LU, C.; CUI, A.; LI, H.; CHEN, X.; XIONG, K.; WANG, M.; LI, M.; PEI, J. et al. Detecting customer complaint escalation with recurrent neural networks and manuallyengineered features. In: Proceedings of the 2019 Conference of the North American Chapter of the Association for Computational Linguistics: Human Language Technologies, Volume 2 (Industry Papers). [S.1.: s.n.], 2019. p. 56-63. Citado nas páginas 23, 25, 31, 32 e 41. 

APÊNDICE

\section{A}

\section{CASO DE USO APLICADO NA INDÚSTRIA}

O objetivo do Mestrado Profissional em Matemática, Estatística e Computação Aplicadas à Indústria é prover uma sólida formação aos alunos com intuito de atender às demandas do setor produtivo de modo a fomentar avanços tecnológicos e desenvolvimento de produtos, tornando assim as empresas mais competitivas e reconhecidas. Neste cenário, este apêndice mostra um caso de uso que utilizou conceitos, técnicas e lições aprendidas apresentados neste trabalho em uma aplicação prática de satisfação de clientes em uma subsidiária de uma instituição financeira brasileira. Por questões de privacidade, os nomes das empresas, alguns detalhes técnicos de implementação e os resultados não serão divulgados.

O caso de uso intitulado "Voz del cliente" tem como objetivo usar técnicas de MT para rotular as respostas dos clientes que podem ser fornecidas pelos mesmos após a avaliação de NPS. O NPS tem como base fazer o seguinte questionamento ao cliente após uma interação:"Qual é a probabilidade de você recomendar essa empresa para um amigo?". O cliente pode fornecer uma resposta de 0 a 10, e com isso o cliente é considerado um detrator com respostas de 0 a 6 , neutro com respostas de 7 a 8 e promotor com respostas de 9 a 10. Após responder a probabilidade, o cliente é questionado em uma pergunta aberta qual seria o motivo pelo qual o cliente deu aquela probabilidade. A resposta do cliente geralmente contém os motivadores que levaram a (in)satisfação em relação a empresa, sendo que estes motivadores são obtidos por meio dos rótulos usando técnicas de MT. Algumas dezenas de motivadores foram definidos em tempo de projeto e alguns exemplos são: atendimento, rapidez-eficácia, interface de usuário, tempo de espera, entrega de cartões, entre outros.

No início do caso um conjunto de técnicas de AM não-supervisionados como modelagem de tópicos e clusterização foram testadas com intuito de atingir o objetivo, porém sem sucesso. A partir disso, um conjunto de analistas empenharam em criar rótulos para uma massa de algumas milhares de respostas dos clientes, que foram utilizadas para treinamento dos modelos. Uma etapa de pré-processamento dos dados foi necessário para correção de palavras, remoção de 
símbolos, pontuações e stopwords. Com as lições aprendidas neste trabalho, foram testados os modelos NBSVM e FastText devido a boa capacidade de predição e o tempo aceitável de processamento. Ao final da fase de modelagem o modelo escolhido foi o FastText que atingiu níveis de acurácia dos motivadores entre $70 \%$ e $90 \%$, sendo que esta métrica estava dentro do nível de aceitação do dono do caso. O produto final deste caso é um dashboard que permite aos analistas entenderem com facilidade quais são os principais motivadores de detração e promoção dos clientes. O dashboard mostrado na Figura 25 tem como requisitos: análises por período de tempo, canal de interação, segmentação dos clientes, gráficos de evolução dos motivadores, nuvem de palavras e amostragem de respostas por motivador.

Figura 25 - Dashboard do caso de uso "Voz del cliente".

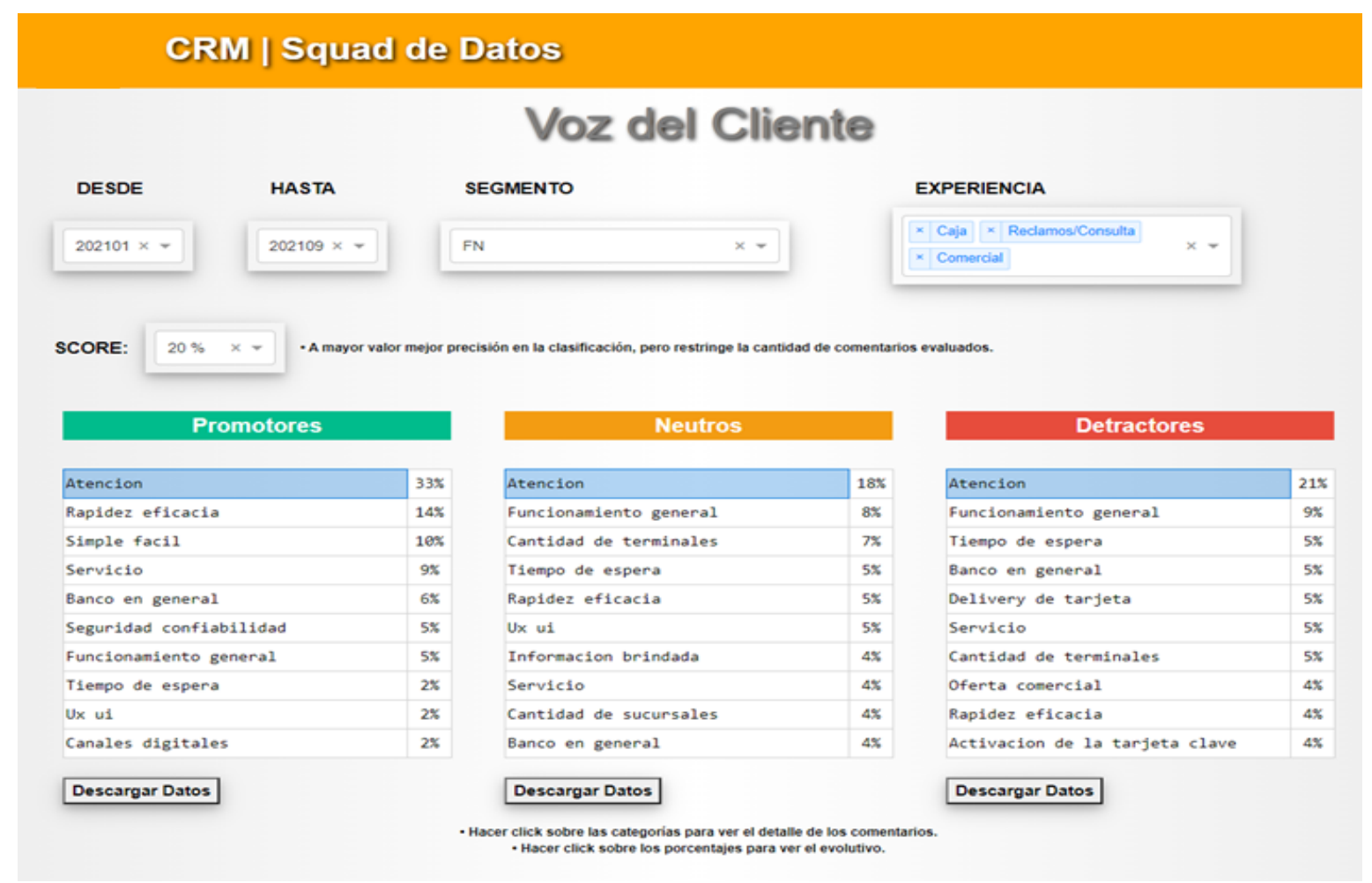

Antes deste caso de uso as respostas não eram utilizadas em escala e uma grande oportunidade de melhoria continua da experiência do cliente foi perdida. Este caso de uso está na fase final de implementação, sendo que após a conclusão do dashboard, as áreas da empresa responsáveis pelas interações com o cliente terão uma ferramenta para diagnóstico dos motivadores de detração e promoção dos clientes. Estes motivadores irão direcionar a evolução dos processos de atendimento promovendo assim a melhoria contínua da experiência dos clientes. 


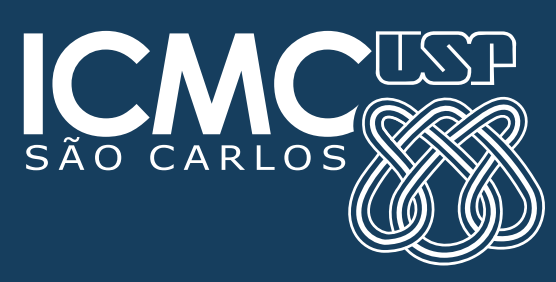

